\title{
Synthesis and Application of Glycopeptide and Glycoprotein Mimetics
}

\author{
Daniel Specker • Valentin Wittmann $(\bowtie)$
}

Fachbereich Chemie, Universität Konstanz, 78457 Konstanz, Germany mail@valentin-wittmann.de

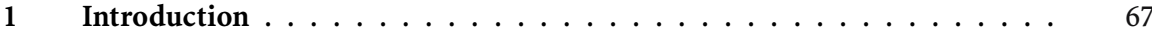

2 Strategies for Assembly of Glycopeptide and Glycoprotein Mimetics . . . .

3 Synthesis of Glycopeptide Mimetics by Linear Assembly of Glycosylated Amino Acids with Unnatural Linkages . . . . . . . . . . 70

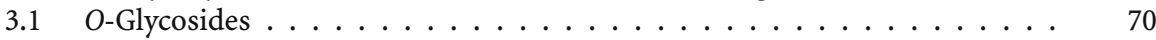

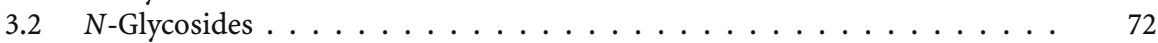

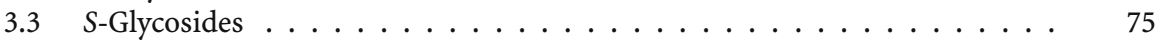

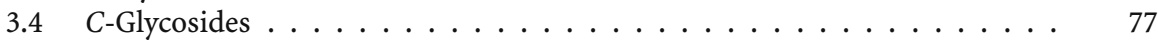

4 Convergent Approaches to Glycopeptide and Glycoprotein Mimetics . . . 82

4.1 Formation of $\mathrm{C}=\mathrm{N}$ Bonds $\ldots \ldots \ldots \ldots \ldots$

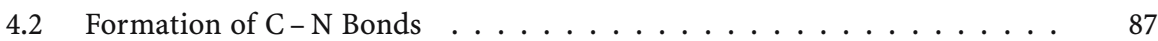

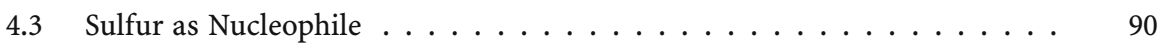

4.3 .1 S-Alkylation . . . . . . . . . . . . . . . . . . . . 90

4.3.2 Conjugate Addition to Michael Acceptors . . . . . . . . . . . . . . . . . . . . . . 93

4.3.3 Disulfide Bond Formation . . . . . . . . . . . . . . . . . . . 95

4.4 Azide-Alkyne $[3+2]$ Cycloaddition . . . . . . . . . . . . . 97

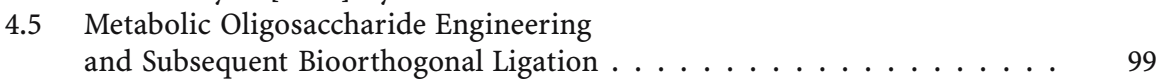

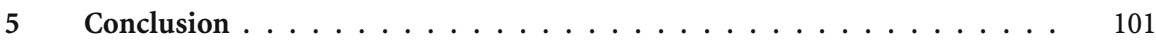

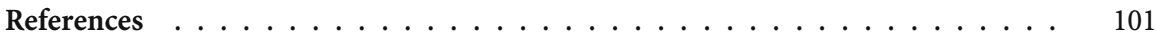

\begin{abstract}
Glycosylation of proteins is the most complex form of posttranslational modification. Glycan chains of glycoproteins are involved in numerous biological recognition events, such as protein folding, cell-cell communication and adhesion, cell growth and differentiation, as well as bacterial and viral infection. As an alternative to glycoprotein synthesis, approaches to the construction of glycopeptide and glycoprotein mimetics have been developed. These so-called neoglycopeptides and neoglycoproteins, respectively, provide insight on the importance of distinct structural elements on biological activity. Furthermore, they may have improved properties, such as increased stability in the case of $S$ - and $C$-glycopeptides. This article summarizes recent progress in the field of synthetic glycosylated amino acids, peptides, and proteins with non-natural structural elements with a focus on the carbohydrate-peptide linkage. Linear and convergent approaches are discussed. Application of chemoselective ligation reactions provides access to pure glycoforms of glycoprotein mimetics.
\end{abstract}

Konstanzer Online-Publikations-System (KOPS)

URL: http://www.ub.uni-konstanz.de/kops/volltexte/2007/4212/

URN: http://nbn-resolving.de/urn:nbn:de:bsz:352-opus-42124 
Keywords Glycopeptides · Glycoproteins · Glycobiology · Neoglycoconjugates ·

Bioconjugation · Chemoselective ligation

\section{Abbreviations}

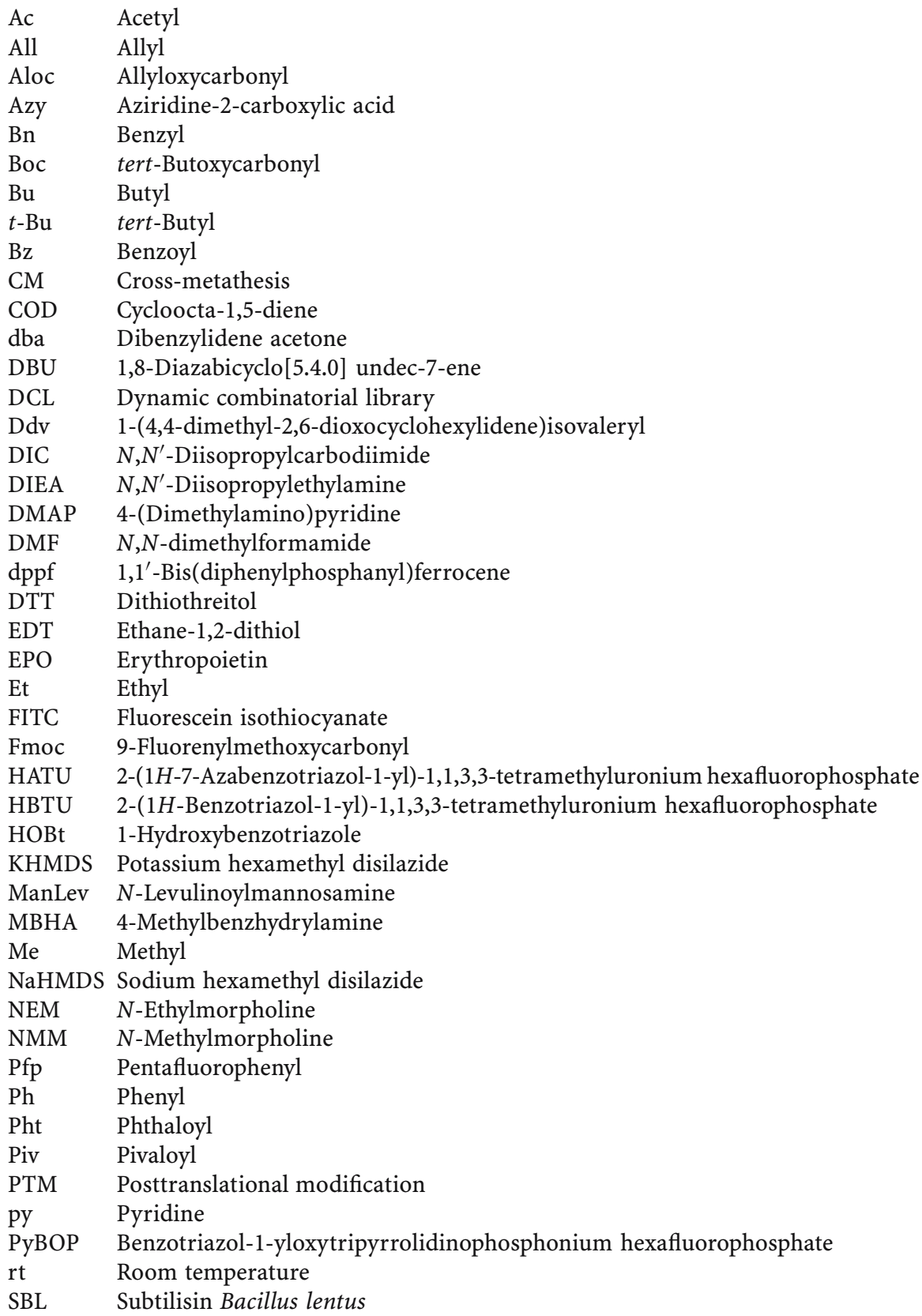




$\begin{array}{ll}\text { SPPS } & \text { Solid-phase peptide synthesis } \\ \text { Su } & \text { Succinimidyl } \\ \text { TBAHS } & \text { Tetra- } n \text {-butylammonium hydrogen sulfate } \\ \text { TBS } & \text { tert-Butyldimethylsilyl } \\ \text { TFA } & \text { Trifluoroacetic acid } \\ \text { Tfa } & \text { Trifluoroacetyl } \\ \text { THF } & \text { Tetrahydrofuran } \\ \text { TIPS } & \text { Triisopropylsilyl } \\ \text { TMS } & \text { Trimethylsilyl } \\ \text { Ts } & \text { Tosyl } \\ \text { Z } & \text { Benzyloxycarbonyl }\end{array}$

1

\section{Introduction}

The most surprising result of the human genome project probably was the fact that our genome consists of less than 30000 genes. This low number underlines the importance of posttranslational modifications (PTMs) in order to reach the complexity of higher organisms. Among the PTM events that are known today, glycosylation is the most complex form and requires about $1 \%$ of mammalian genes [1]. The functions of the glycan chains of glycoproteins span the complete spectrum from being essentially unimportant to being crucial for the survival of an organism [1-10]. Glycan chains of glycoproteins modulate physicochemical properties of proteins, such as solubility, viscosity, charge, conformation, and dynamics and thereby can bestow stability and resistance to proteolytic degradation and can lead to improved protein efficacy. On the other hand, the glycans provide unique epitopes for molecular recognition that are involved in cell-cell communication, cell growth and differentiation, cancer metastasis, bacterial and viral infection, and they direct protein folding.

Oligosaccharides are attached to proteins mainly via an $\mathrm{N}$-glycosidic bond to asparagine (Fig. 1) or an $\mathrm{O}$-glycosidic bond to hydroxylated amino acids,

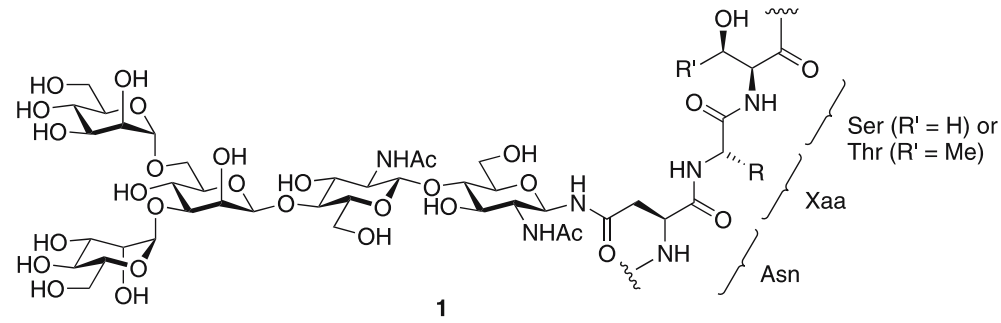

Fig. 1 Common structure of all $N$-glycoproteins: core pentasaccharide attached to the consensus sequence Asn-Xaa-Ser/Thr 


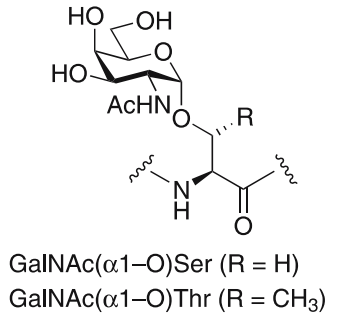

2

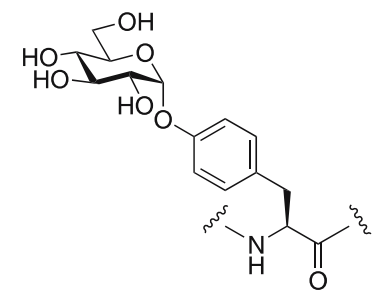

Glc $(\alpha 1-0)$ Tyr

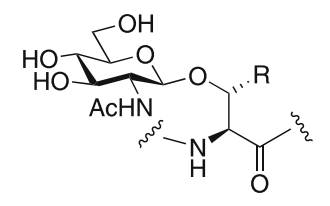

$\operatorname{GlcNAc}(\beta 1-\mathrm{O}) \operatorname{Ser}(\mathrm{R}=\mathrm{H})$

$\operatorname{GlcNAc}(\beta 1-\mathrm{O}) \operatorname{Thr}\left(\mathrm{R}=\mathrm{CH}_{3}\right)$

3

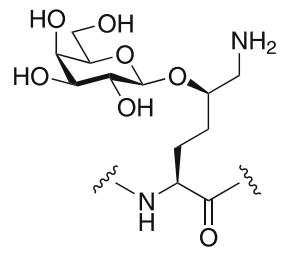

$\mathrm{Gal}(\beta 1-\mathrm{O}) \mathrm{Hyl}$

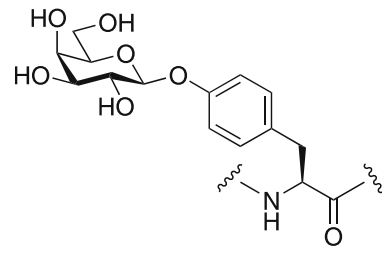

$\mathrm{Gal}(\beta 1-0) \mathrm{Tyr}$

6

Fig. 2 Selected carbohydrate-peptide linkages found in $O$-glycoproteins

such as serine and threonine (Fig. 2) [11-15]. Whereas all $N$-glycoproteins share the same core structure 1 , which is derived from a common biosynthetic oligosaccharide precursor, a variety of carbohydrate-peptide linkages are found in $O$-glycoproteins. In the mucins, the GalNAc $(\alpha 1-\mathrm{O}) \operatorname{Ser} / \mathrm{Th}$ linkage 2 (also called Tn antigen) is found. Another widely occurring $O$-glycosidic bond is the GlcNAc $(\beta 1-\mathrm{O})$ Ser/Thr linkage 3. Less common O-glycosidic linkages include those to hydroxylysine $(4)$ and tyrosine $(5,6)$.

Since the glycan chains are secondary gene products that are not synthesized in a template-controlled fashion, they usually occur as complex mixtures of glycoforms, making their isolation and analysis a demanding task. Chemists, therefore, have developed synthetic strategies for the preparation of pure glycoforms of proteins required for the evaluation of structurefunction relationships [16-26]. The total synthesis of glycoproteins, however, is still an enormous challenge and remains the domain of a few specialized laboratories around the world.

The synthesis of glycopeptide and glycoprotein mimetics, also referred to as neoglycoconjugates [27], represents an alternative strategy to produce single glycoforms for biological studies. The replacement of a natural structure with a non-natural one allows study of the influence of distinct structural elements on biological activity, but has many practical applications as well. Use of chemoselective ligation reactions makes glycoconjugate synthesis accessible to a broader community. Furthermore, $S$ - and $C$-glycosidic bonds for example are more stable than the corresponding $O$-glycosides (both chemi- 
cally and with respect to enzymatic degradation), which leads to an increased half life of a glycoconjugate within a biological system. Thus, beneficial properties of glycans may be permanently linked to a protein, which is an important aspect for pharmaceutical applications. This article summarizes recent progress in the field of synthetic glycosylated amino acids, peptides, and proteins with non-natural structural elements, with a focus on the carbohydratepeptide linkage. For a more complete coverage of this wide area, the reader is referred to other excellent reviews [23, 28-38].

\section{2}

\section{Strategies for Assembly of Glycopeptide and Glycoprotein Mimetics}

Scheme 1 summarizes the main strategies that have been explored in the past for the preparation of glycopeptide and glycoprotein mimetics. Two major approaches can be distinguished: the linear and the convergent assembly. In the linear assembly, carbohydrates are coupled to amino acids 7 to give modified amino acids carrying either mono- (8) or oligosaccharides (10). These are used as building blocks in solution or (more commonly) solid-phase pep-

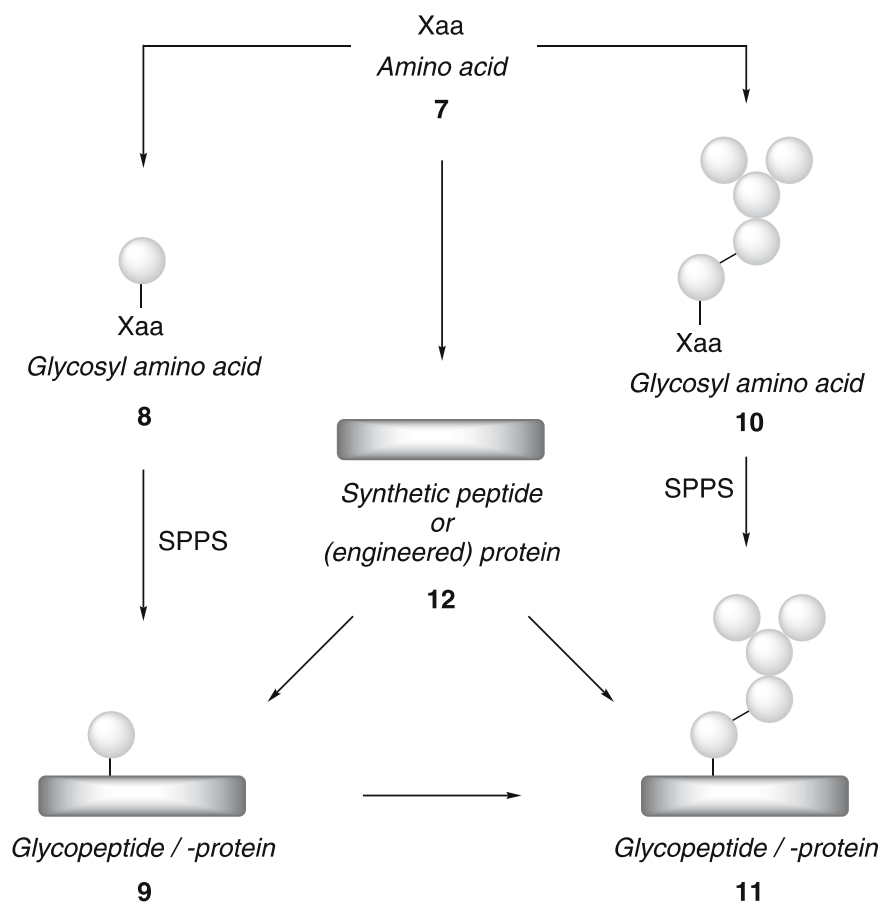

Scheme 1 Linear and convergent strategies that have been employed for the synthesis of glycopeptide and glycoprotein mimetics 
tide synthesis (SPPS) to provide glycoconjugates 9 and 11, respectively. Linear approaches are covered in Sect. 3 of the article. In convergent approaches, carbohydrates are coupled to presynthesized peptides or to proteins (12) to give 9 and 11. Depending on the type of chemistry used for carbohydrate attachment, there might be a need for protecting groups at the peptide and carbohydrate, an approach which is confined to synthetic peptides. Conjugation of carbohydrates to full-length proteins is possible via chemoselective ligation to amino acids with a unique reactivity, for example cysteine residues. Combined with site-directed mutagenesis, this approach allows for control of both site of attachment and type of saccharide. Alternatively, genetically engineered proteins containing non-proteinogenic amino acids with a unique chemical reactivity can be employed.

Mixed linear and convergent assembly strategies have also been described. Glycopeptide mimetics 9 or 11 synthesized by the linear route have been extended in the glycan part by convergent attachment of an oligosaccharide through chemoselective ligation. Convergent and mixed approaches for assembly of glycopeptide and glycoprotein mimetics are dealt with in Sect. 4 . Not shown in Scheme 1 are the assembly of peptide and neoglycopeptide fragments by native chemical ligation [39] and the incorporation of nonproteinogenic glycosylated amino acids into proteins by in vivo suppressor tRNA technology [40-42].

3

\section{Synthesis of Glycopeptide Mimetics by Linear Assembly of Glycosylated Amino Acids with Unnatural Linkages}

\section{1 \\ O-Glycosides}

Several groups have described building blocks for the preparation of glycopeptide mimetics containing $\mathrm{O}$-glycosidic bonds. Based on chemistry developed earlier [43], Nativi et al. prepared $\alpha$-O-linked glycohomoglutamates 16 as replacement for naturally occurring $\alpha$-O-glycopeptides found in mucins (Scheme 2) [44]. $\beta$-Ketoesters 13 obtained from aspartic acid and Meldrum's acid were reacted with phthalimidosulfenyl chloride. Base treatment of 14 gave reactive intermediate 15 , which underwent a hetero Diels-Alder reaction with glycals to give $\alpha$-O-glycohomoglutamates 16 as diasteriomerically pure isomers. The same approach has been used by Franck et al. for the preparation of $N$-glycosides [45].

Preparation of the four galactosylated 5-hydroxylysine mimetic building blocks 19-22 was accomplished by Guichard and coworkers (Scheme 3) [46]. The synthesis of the 5-hydroxy amino acid derivative 18 started from hydroxylated piperidinone 17. Subsequent galactosylation gave 19 . The use of 
<smiles>[R]OC(=O)CC(=O)CC(N)C(=O)OCc1ccccc1</smiles>
13

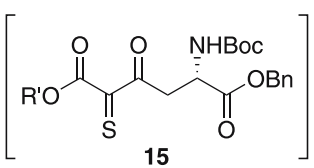
15

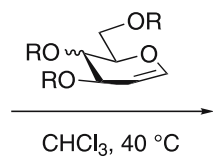<smiles>[R]OC(=O)C([AsH2])C(=O)C[C@H](N)C(=O)OCc1ccccc1</smiles>

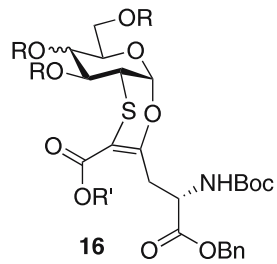

Scheme 2 Preparation of $\alpha$-O-glycohomoglutamates 16 through hetero Diels-Alder reaction with glycals

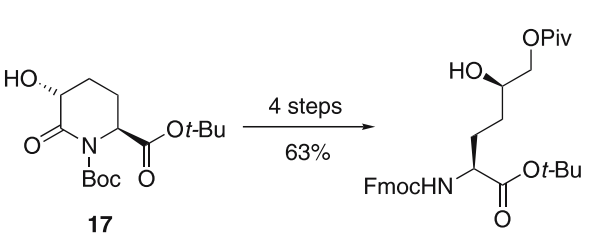

18

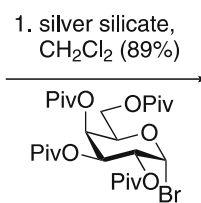

2. TFA (quant.)

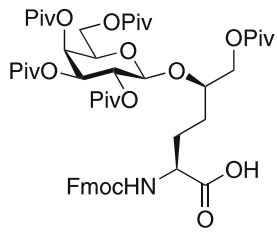

19

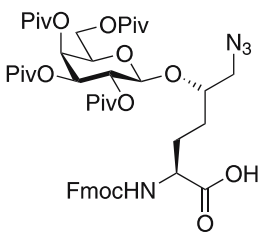

20

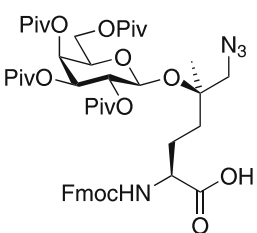

21

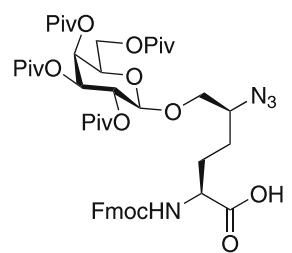

22

Scheme 3 Synthesis of building blocks for the preparation of collagen mimetics

pivaloyl-protected galactosyl bromide prevented undesired orthoester formation during the glycosylation step. Building blocks 20-22 were obtained analogously. The galactosylated hydroxylysine mimetics were incorporated into bovine type II collagen (bCII) immunodominant glycopeptides in order to study the fine specificity of bCII-reactive $\mathrm{T}$ cells involved in the initiation and/or regulation of collagen-induced arthritis, a mouse model for rheumatoid arthritis [47].

Danishefsky et al. applied $\beta$-O-allyl glycosides of mono- and oligosaccharides, including the breast and prostate cancer antigen Globo- $\mathrm{H}$, for a crossmetathesis reaction with Fmoc-L-allylglycine benzyl ester, followed by reduction of the resulting olefins via catalytic hydrogenation, with the concomitant release of the free acid [48]. The obtained non-natural glycosyl amino acids can readily be applied in solid-phase synthesis of potential glycopeptidebased antitumor vaccines. 
Peptoids (N-substituted oligoglycines) are peptide mimetics that are characterized by an improved proteolytic stability and high conformational flexibility $[49,50]$. Roy and coworkers were the first to synthesize glycosylated derivatives of peptoids, which they named glycopeptoids. Several O-linked [51,52] but also N-linked [53,54] and C-linked [52] variants were prepared and used as building blocks for the construction of HIV-1 protease inhibitors [55] and Tn-antigen clusters [56].

Glycopeptide mimetics with a modified peptide backbone in order to reduce biodegradability have been reported by Shin et al. [57]. They synthesized the pentamers 23 and 24 containing $\mathrm{O}$ - and $\mathrm{N}$-glycosylated $\alpha$-aminooxy acids by fragment coupling on solid support (Scheme 4).

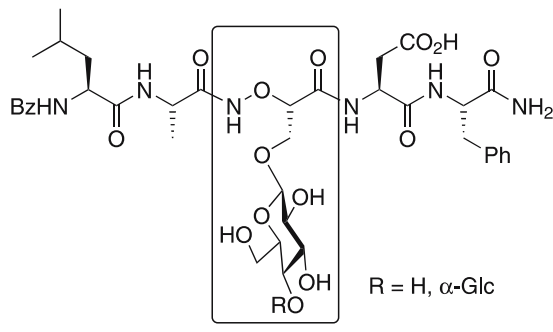

23

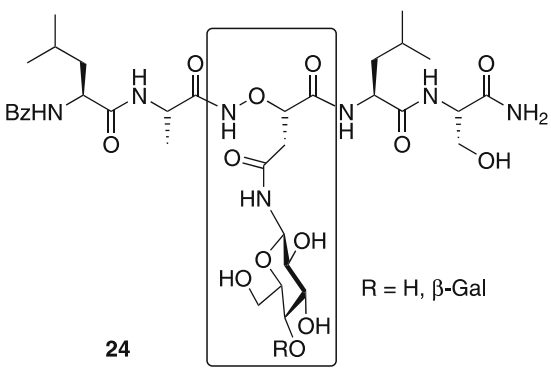

Scheme 4 Glycopeptide mimetics with a peptide backbone containing O- and N-glycosylated $\alpha$-aminooxy acids

\section{2}

\section{$\mathrm{N}$-Glycosides}

In recent years, the copper(I)-catalyzed [3+2] cycloaddition of azides and alkynes $[58,59]$ (often referred to as "click" reaction) has found wide application in the field of bioconjugation [60], including the preparation of glycopeptide mimetics. Depending on whether the azide or the alkyne component is connected to the carbohydrate, $\mathrm{N}$-glycosides and $\mathrm{C}$-glycosides, respectively, are obtainable. Rutjes and coworkers reacted various glycosyl azides 25 with a series of acetylenic amino acids 26 to obtain triazole-linked glycosyl amino acids 27 and also some peptides (Scheme 5) [61]. With a few exceptions, the yields were generally good to excellent. The triazole linkage appeared to be stable under several acidic and basic conditions (e.g., $1 \mathrm{M} \mathrm{HCl}$ in $\mathrm{MeOH}$, $6 \mathrm{~h}$, reflux or $1.25 \mathrm{M}$ aqueous $\mathrm{NaOH}, 24 \mathrm{~h}$, reflux). Using $\alpha$ - and $\beta$-glycosyl acetylenes, several C-glycosidically linked triazole-containing glycosyl amino acids were synthesized.

The azide-alkyne cycloaddition was also employed for the preparation of carbohydrate-modified $2(1 \mathrm{H})$-pyrazinones as precursors of glycopep- 


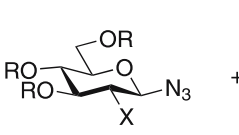

25

$\mathrm{R}=\mathrm{Ac}, \mathrm{Bn}, \mathrm{Bz}$

$X=O R, N H A C$

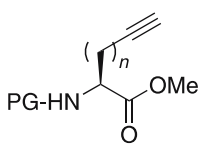

26

$P G=$ Boc, Fmoc, Ts $n=1,2,3$
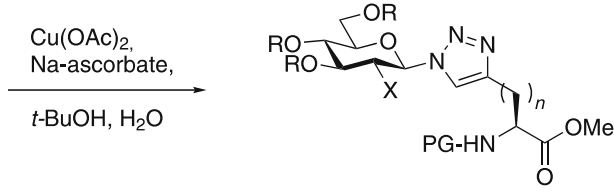

27

Scheme 5 Application of the azide-alkyne cycloaddition for the preparation of triazolelinked glycosyl amino acids

tidomimetics [62] and also for the preparation of glycopeptide and glycoprotein mimetics by convergent strategies (cf. Sect. 4.4).

A different approach towards non-natural $N$-glycosyl amino acids was reported by Klaffke and coworkers [63, 64]. They used disaccharides $N$-glycosidically linked to spacers bearing a second amino function at the other end. This primary amine was linked to the $\gamma$-carboxamide function of glutamine within the dipeptide Z-Gln-Gly-OH in a reaction catalyzed by the enzyme transglutaminase. The needed spacer-modified $\mathrm{N}$-glycosides were accessible by reaction of the disaccharide (e.g., maltose) with allylamine followed by acetylation and photochemical thioetherification with cysteamine hydrochloride.

Starting from azido-functionalized glucuronic acid 28, Lindhorst and coworkers prepared glycosyl amino acids with a dendron moiety attached to the sugar giving access to branched glycopeptide mimetics of variable sugar composition (Scheme 6) [65]. Serving as the branching element, amino triester 29 was introduced under standard peptide coupling conditions. Resulting 30

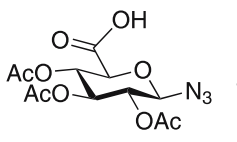

28<smiles>O=C(O)CC(N=CP)C(=O)OCc1ccccc1</smiles>

$\mathrm{DIC}, \mathrm{HOBt}, \mathrm{PMe}_{3}$

THF, $0{ }^{\circ} \mathrm{C}$ to rt

$59 \%$

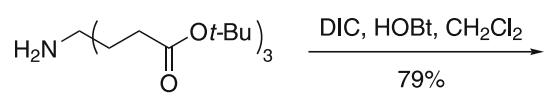

29

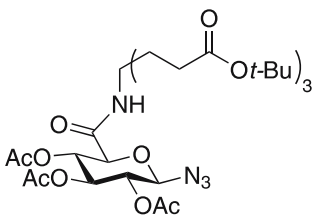

30

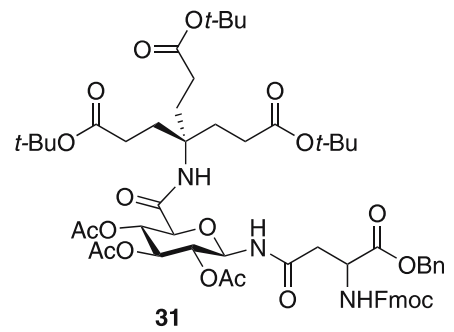

Scheme 6 Application of a modified Staudinger reaction for the synthesis of dendronfunctionalized $N$-glycoside 31 
was converted into the dendron-functionalized $N$-glycoside 31 via a modified Staudinger reaction.

Van Ameijde and Liskamp coupled N-linked glyco amino acid building blocks, in which glycosyl amines are connected to the carboxy group of an amino acid via an amide bond, to trivalent cyclotriveratrylene scaffolds with varying spacers [66]. The obtained glycoclusters can be used to study multivalent interactions. Ichikawa et al. explored the use of Steyermark's glucopyranosyl oxazolidinone for anchoring glucosyl moieties onto amines and thiols in aqueous media [67]. The method was applied for the synthesis of a urea-tethered glucosyl lysine conjugate and a corresponding cysteine conjugate.

Thiem and coworkers prepared a $N^{4}$-(2-acetamido-2-deoxy- $\beta$-D-glucopyranosyl)-L-asparagine analogue in which the side-chain carboxy group of aspartic acid is linked to the 2-amino function of 1,5-anhydro-2-amino-2deoxyglucitol [68]. The building block was incorporated into a mimic of the V3 loop of the HIV-1 gp 120 envelope glycoprotein by solid-phase peptide synthesis (SPPS).

Inspired by the work of Roy et al. [53,54], already mentioned in Sect. 3.1, Burger and coworkers reported a preparatively simple synthesis of $\mathrm{N}$-linked glycopeptoids starting from iminodiacetic acid using hexafluoroacetone as protecting and activating reagent (Scheme 7) [69]. Dielectrophile 32 reacts with weak nucleophiles such as glycosylamine 33 at the more reactive acid chloride to give the N-glycosylated activated glycine derivative 34 . Treatment with sarcosine-tert-butylester provided dipeptoide 35 under concurrent deprotection of the $\alpha$-amino group. N-Terminal elongation with 36 gave tripeptoide 37.

Vankar and coworkers recently introduced the novel reagent system trimethylsilylnitrate/trimethylsilyl azide for the synthesis of 2-deoxyglycosyl
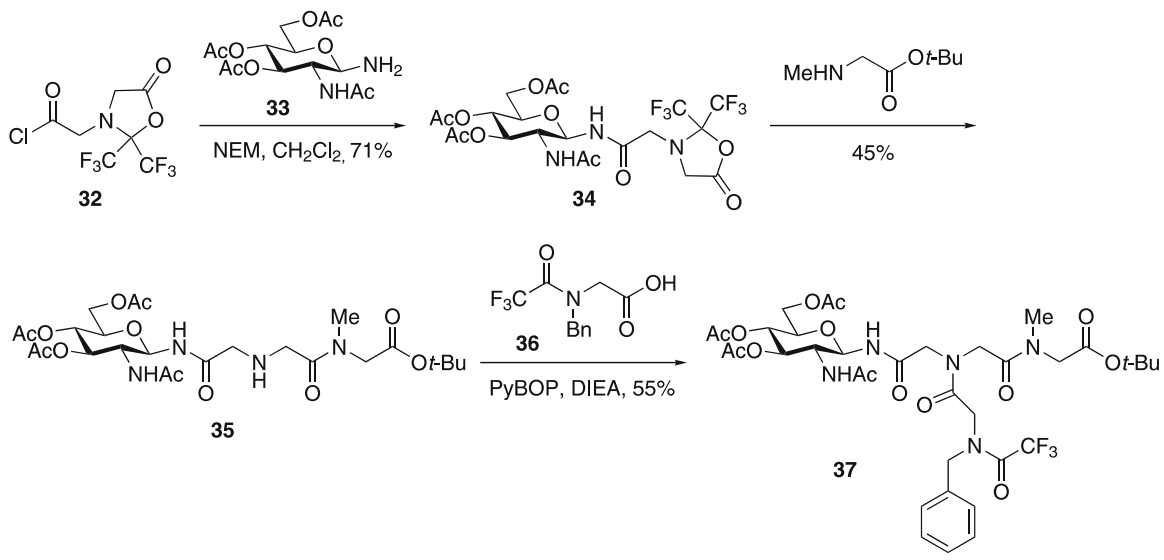

Scheme 7 Synthesis of N-linked glycopeptoide 37 
azides from glycals [70]. After Staudinger reduction, the obtained glycosylamines were applied in the synthesis of 2-deoxy- $\beta$ - $N$-glycopeptides.

\section{3}

\section{S-Glycosides}

Replacement of the anomeric oxygen of $O$-glycosides by sulfur to furnish $S$-glycosides leads to an increased stability towards acid/base and enzymatic hydrolysis. The preparation of S-linked glycopeptides/proteins has been covered by several excellent reviews $[23,32,38,71]$, most notably a very recent one by Pachamuthu and Schmidt [28]. The present article, therefore, will focus on selected examples.

In the past, two main strategies have been employed for the synthesis of S-linked glycosyl amino acids. One uses an anomeric thiolate nucleophile, which is generally configurationally stable, in $S_{N} 2$ reaction with a halogenfunctionalized amino acid, often a 3-bromoalanine derivative. The major side reactions are disulfide formation via air oxidation and $\beta$-elimination to the corresponding dehydroalanine followed by Michael addition, which results in an epimeric mixture at the $\alpha$-carbon of the amino acid product. Alternatively, a thiol-containing amino acid, e.g., cysteine or homocysteine, is glycosylated by reaction with a glycosyl donor. The reaction can be carried out under basic conditions employing a halogenose leading to an $\mathrm{S}_{\mathrm{N}} 2$ displacement. This is particularly convenient for equatorial $S$-glycosides because the halogen atom is generally found in the axial position. Access to axial thioglycosides is given by acid-catalyzed S-glycosylation following an $\mathrm{S}_{\mathrm{N}}$ 1-type mechanism.

Knapp and Myers used thiazolines 38, derived from peracetylated glucosamine and galactosamine, respectively, by treatment with Lawesson's reagent, for the formation of $\alpha$-GlcNAc and $\alpha$-GalNAc thiols 39 (Scheme 8a) $[72,73]$. Alkylation with 3-iodoalanine derivative $\mathbf{4 0}$ in the presence of base provided the S-glycosylated amino acids 41 in high yields without apparent epimerization at the $\alpha$-carbon of the amino acid.

A similar approach was applied by Zhu and Schmidt for the synthesis of S-glycosylated amino acids and di- and tripeptides 44 (Scheme 8b) $[74,75]$. They reacted $\alpha$-GlcNAc and $\alpha$-GalNAc thiols 39 as well as $\beta$-GlcNAc and $\beta$-lactosyl thiols with 3-bromoalanine (42) and 4-bromohomoalanine derivatives (43) under phase transfer conditions or in a mixture of DMF and water at $\mathrm{pH}$ 8.5. Due to the mild conditions, epimerization was not observed and even Fmoc-protected peptides were applicable.

Wong et al. modified the procedure and developed a two-step one-pot reaction with in situ generation of sugar thiolates 46 (Scheme 9) [233]. Glycosyl thioacetates 45 were first S-deacetylated with $\mathrm{NaOH}$ in methanol at $\mathrm{pH} 7.5$ followed by reaction with Boc- and Fmoc-protected 3-bromoalanines 47 to get a great variety of S-linked glycosyl amino acids 48 . Two of them were incorporated into a linear and a cyclic analogue of the cyclic cationic decapeptide 
a)
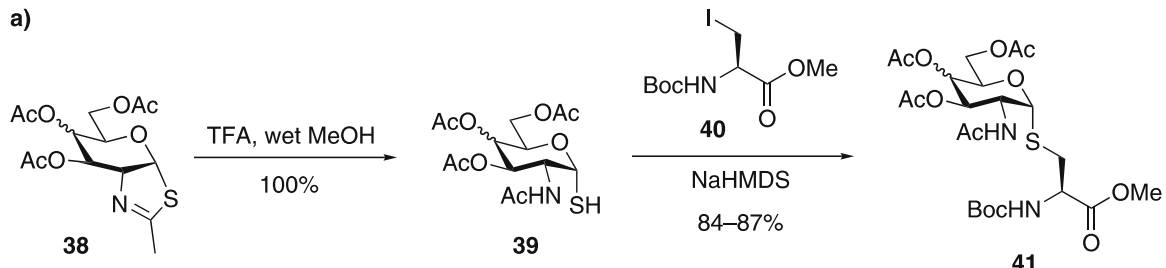

b)
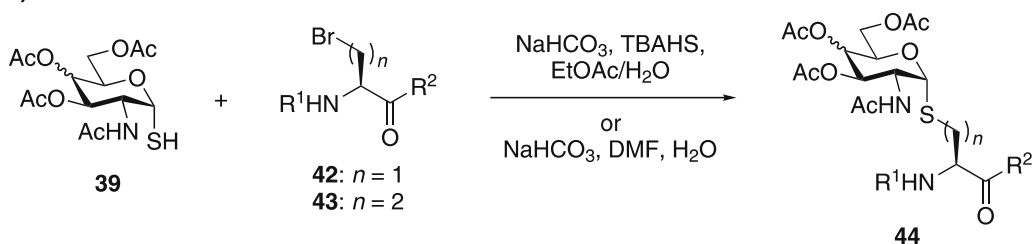

Scheme 8 Approaches to S-linked glycosyl amino acids using anomeric thiolate nucleophiles

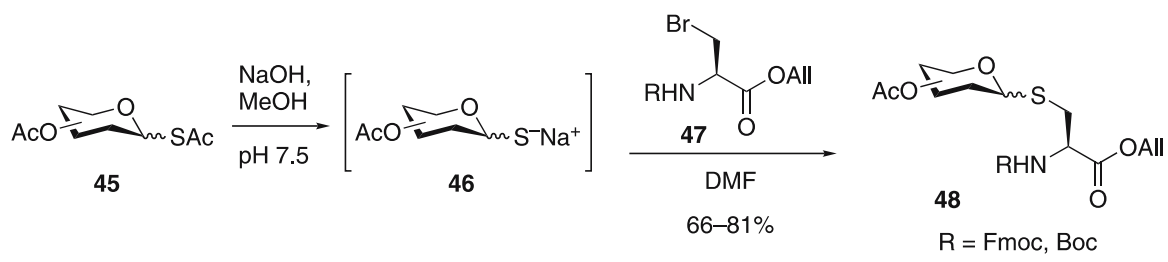

Scheme 9 A two-step one-pot reaction for the preparation of S-linked glycosyl amino acids 48 generating sugar thiolates 46 in situ

antibiotic tyrocidine A, which is produced in Bacillus brevis. The cyclic analogue was shown to have a better antibiotic profile than tyrocidine A.

An efficient solid phase strategy for the synthesis of $\beta$-S-glycosyl amino acids 51 was described by Jobron and Hummel (Scheme 10) [76]. Based on an earlier report [77], they used unprotected sugar thiols immobilized via the 6 position to generate sodium thiolates $\mathbf{4 9}$ for nucleophilic attachment to different iodine-substituted Fmoc-protected amino acids $\mathbf{5 0 .}$

For the stereoselective synthesis of S-linked glycosyl amino acids, e.g., 55 and 56, Cohen and Halcomb prepared serine- and allo-threonine-derived
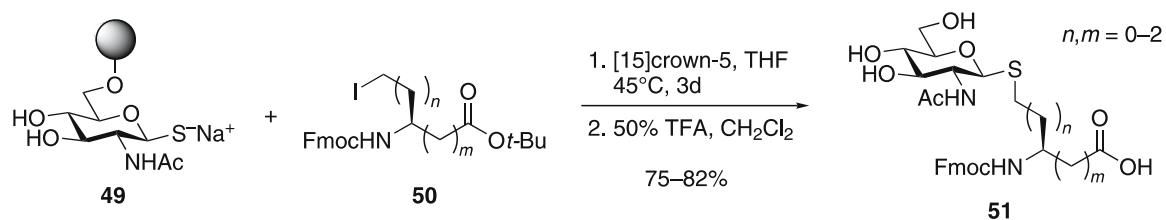

Scheme 10 Solid-phase synthesis of $\beta$-S-glycosyl amino acids $\mathbf{5 1}$ 

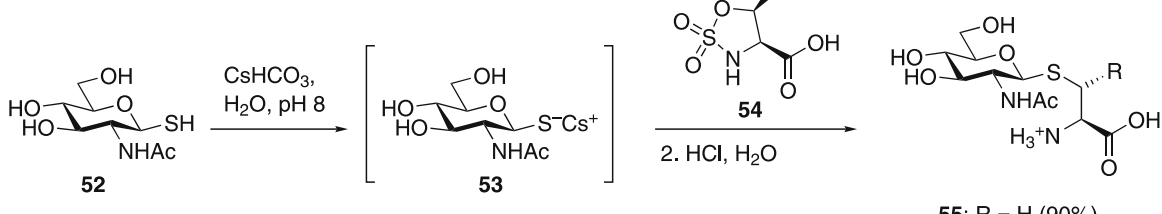

55: $\mathrm{R}=\mathrm{H}(90 \%)$

56: $R=\operatorname{Me}(60 \%)$

Scheme 11 Application of cyclic sulfamidates $54(\mathrm{R}=\mathrm{H}, \mathrm{Me})$ for the synthesis of S-linked glycosyl amino acids

cyclic sulfamidates $54(\mathrm{R}=\mathrm{H}, \mathrm{Me})$ (Scheme 11) $[78,79]$. In their approach, the sulfamidates reacted with in situ-formed $\beta$-cesium thiolates, such as 53, to give the unprotected thioglycosides after hydrolysis of the $N$-sulfates. The use of cesium as the counter ion afforded higher yields due to an increased solubility of the thiolate, allowing the application of higher concentrations. The serine-derived sulfamidate was also incorporated into a peptide on a solid support. Addition of a 1-thio sugar afforded a solid-phase bound $S$-glycodipeptide, which could be extended to a tripeptide using standard peptide synthesis procedures.

Direct base-catalyzed S-glycosylation of cysteine- and homocysteinecontaining peptides using protected glycosyl bromides was reported by Schmidt and coworkers [80]. They reacted cysteine-centered tripeptides, which were accessible via chemical ligation, with peracetylated glucosyl and lactosyl bromides under two-phase conditions and observed the formation of S-linked glycopeptides in very good yields. The strategy was also applied for the synthesis of an S-linked glycopeptide analogue derived from human Tamm-Horsfall glycoprotein in the same laboratory [81].

Two types of novel $S$-neoglycopeptides were published by Schmidt et al. [82]. Glycosylthiomethyl amides were obtained by reaction of glycosylthiomethyl azides with amino acids and peptides containing aspartate and glutamate thio acids, whereas reaction of glycosylthiomethyl bromides with cysteine and homocysteine derivatives afforded the corresponding $S$-(glycosylthiomethyl) amino acids and peptides.

\section{4}

\section{C-Glycosides}

The existence of $C$-glycosidic linkages in naturally occurring glycoproteins was first discovered in 1994 in human RNase, in which a mannose residue is connected to C2 of the indole ring of a tryptophan [83]. A few years later, Manabe and Ito established the synthesis of a corresponding building block, which opened the way for the incorporation of ${ }^{13} \mathrm{C}$ or ${ }^{15} \mathrm{~N}$ labels [84]. However, even before the discovery of the $C$-mannosyl-tryptophan linkage, carbonlinked glycosyl amino acids have attracted the interest of synthetic chemists 
because of the stability of this linkage. $C$-Glycosyl glycines for example were reported as early as in the late 1940s [85]. Yet, it took until 1992 to incorporate $C$-glycosyl amino acids into peptides. Kessler et al. synthesized $C$-glycosyl alanine derivatives via free radical addition to dehydroalanine derivatives and dehydroalanine-containing peptides [86]. Bertozzi et al. reported on a $C$ glycosyl analogue of $\mathrm{Gal}(\beta 1-\mathrm{O}) \operatorname{Ser}$ (i.e., a $C$-glycosyl homoalanine) and its use for SPPS of an $\alpha$-helical $C$-glycopeptide [87]. Since then, C-linked glycopeptides have been extensively studied by many groups as an approach to obtain stable glycopeptide mimetics and several review articles cover this subject $[32,35,38]$. Selected recent publications will be presented.

Nucleophilic attack at the anomeric carbon is a common pathway towards $C$-glycosides $[88,89]$. Following this approach, Kihlberg et al. synthesized the C-linked isostere 62 of $\beta$-D-galactosyl hydroxynorvaline (Scheme 12) [90]. The two key steps in this synthesis were the addition of a homoallylic Grignard reagent to per-O-benzylated galactopyranolactone 57 with subsequent reduction of the resulting hemiacetal with triethylsilane and a Wittig reaction of phosphonium salt 59 employing Garner's aldehyde 60. Building block 62 was then incorporated into a fragment from type II collagen by solidphase synthesis. Helper $\mathrm{T}$ cell hybridomas obtained in a mouse model for rheumatoid arthritis responded to the C-linked glycopeptide when presented by class II MHC molecules although at a higher concentration compared to the natural O-glycosylated hydroxynorvaline.
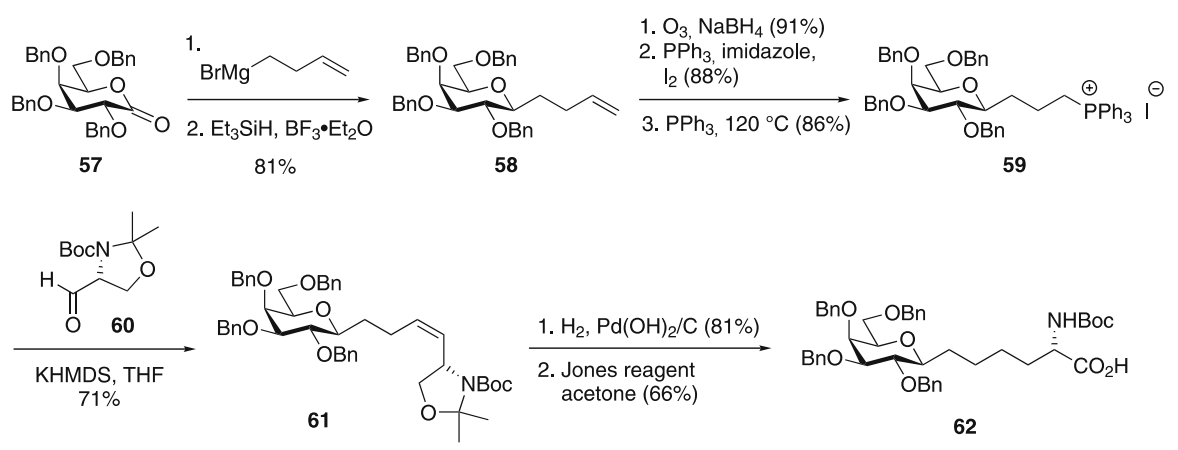

Scheme 12 Synthesis of the C-linked isostere 62 of $\beta$-D-galactosyl hydroxynorvaline from galactopyranolactone 57

On the basis of these results, the same group succeeded in 2003 in the stereoselective synthesis of a $C$-glycoside analogue of $\beta$-D-galactosyl threonine in 14 steps [91]. Recently they reported the synthesis of a $C$-glycoside analogue of $\beta$-D-galactosyl hydroxylysine in 17 steps [92]. An Evans allylation established the configuration at the $\gamma$-carbon of hydroxylysine and an asymmetric hydrogenation using Burk's catalyst was applied for the $\alpha$-amino acid moiety. 
Schweizer and coworkers demonstrated that ulosonic acids, which are accessible from the corresponding sugar lactones by reaction with tertbutylacetate, can be converted into unnatural $C$-glycosyl amino acids via a one-pot intramolecular Ritter reaction [93]. A diaminobutyric acid-derived building block was used as serine replacement in the solid-phase synthesis of a modified opioid peptide.

The stereoselective synthesis of $C$-glycosyl analogues of phenylalanine was reported by Sinou and coworkers (Scheme 13) [94]. Condensation of hex-2enopyranoside 63 with an aryl Grignard reagent [95] afforded unsaturated $\alpha$-C-aryl glycoside 64 , which was subjected to a Heck coupling with acrylate 65. The obtained enamide ester 66 was hydrogenated with a chiral DuPHOS$\mathrm{Rh}^{+}$catalyst and subsequently dihydroxylated to give $C$-mannopyranosyl phenylalanine 68 .
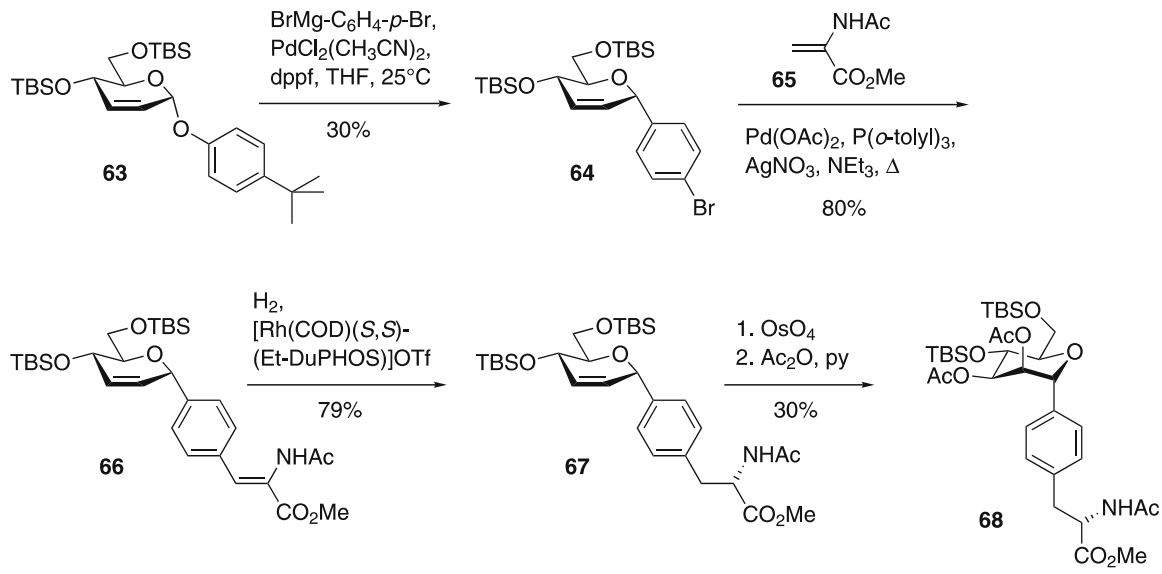

Scheme 13 Synthetic route to $C$-mannopyranosyl phenylalanine 68

For the gram-scale preparation of the $C$-glucosyl phenylalanine derivative 73, Augé and coworkers used the Negishi cross-coupling as key reaction (Scheme 14) [96]. High-yield coupling of $p$-iodo-L-phenylalanine 70 to silylated glycal 69 gave 71. Further protecting group manipulations and stereoselective hydroboration of the double bond yielded C-glycosylated amino acid 73, ready for use in SPPS.

Gallagher et al. employed organozinc reagents carrying an aryl iodide function for the reaction with glycals [97]. Cross-coupling of the aryl iodide to an alanyl zinc reagent by $\operatorname{Pd}(0)$ catalysis led to $C$-glycosyl analogues of glycosyl tyrosines. A C-mannosylated building block was incorporated into a cyclic hexapeptide by solid-phase synthesis.

Through cross-coupling of C-linked glycosyl acetylenes with racemic $N^{\alpha}$ acetyl-3- and -4-iodophenylalanine methyl esters by $\operatorname{Pd}(0)$ catalysis Meldal et al. received diastereomeric pairs of $C$-glycosylacetylene phenylalanine 

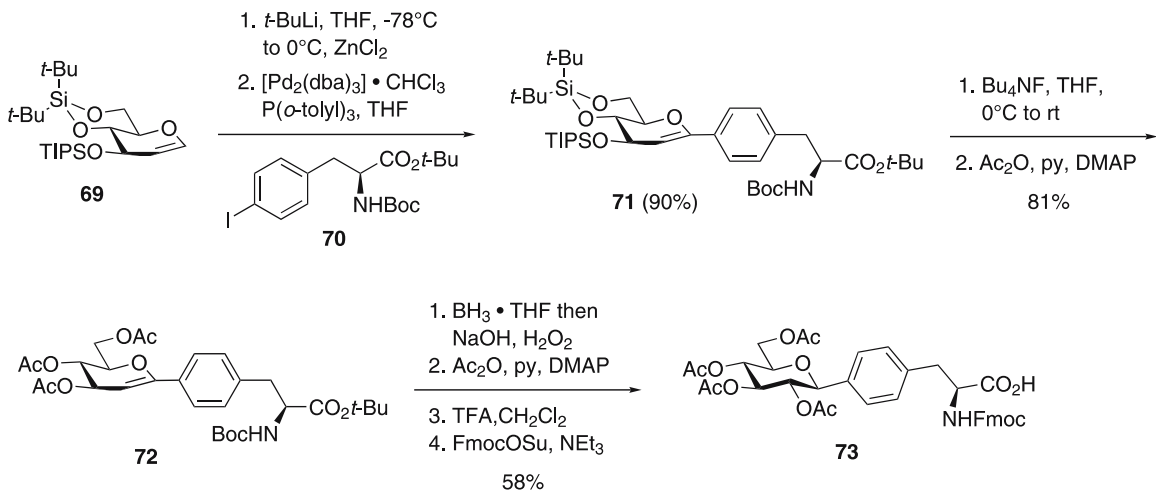

Scheme 14 Application of the Negishi cross-coupling as key step for the synthesis of C-glycosylated phenylalanine $\mathbf{7 3}$

building blocks [98]. Separation of the diastereoisomers was achieved by selective enzymatic hydrolysis of the $N^{\alpha}$-acetyl group of the L-amino acid by acylase I. After Fmoc protection, the building blocks were used in the solidphase synthesis of neoglycopeptide analogues of the mouse hemoglobinderived decapeptide $\mathrm{Hb}(67-76)$. Dondoni et al. used this kind of sugar acetylene for the syntheses of ethylene isosteres 76 of $N$-glycosyl asparagines by coupling of metalated sugar acetylenes 74 with the Garner aldehyde $\mathbf{6 0}$ (Scheme 15) [99].

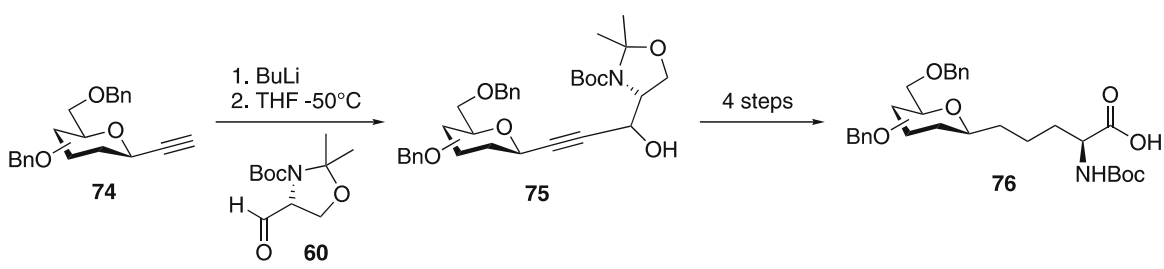

Scheme 15 Synthesis of ethylene isosteres 76 of $N$-glycosyl asparagines from metalated sugar acetylenes $\mathbf{7 4}$

For the synthesis of $C$-glycosyl alanine derivatives, Wong and coworkers used an asymmetric Strecker reaction starting from $C$-glycosyl acetaldehyde derivatives [100]. The stereoselectivity of this reaction was strongly solvent-dependent and was reversed by changing from THF to $\mathrm{CH}_{2} \mathrm{Cl}_{2}$. Starting with the same type of C-glycosidically linked aldehyde, Arya and coworkers succeeded in the synthesis of carbon-linked analogues of $\alpha$-and $\beta$-galactosyl-serine glycoconjugates using asymmetric enolate methodology [101]. Methylene-elongated serine and threonine $C$-glycosyl amino acid building blocks were prepared by Thiem et al. employing regio- and stereo- 
selective aziridine ring opening methodology [102]. The needed $C$-glycosyl aldehyde intermediate was assembled by reaction of peracetylated $\beta$-Dgalactopyranose with propargyl trimethyl silane in the presence of a Lewis acid, similar to a procedure developed by Bednarski et al. [103]. Wang and Linhardt reported the synthesis of serine-based neuraminic acid $C$-glycosides by using a neuraminic acid-based glycosyl donor in a samarium diiodidemediated C-glycosidation reaction [104].

Despite early reports on the use of free radical reactions for the synthesis of $C$-glycosyl amino acids and peptides [86, 105], this approach is still rarely used in comparison to the above-mentioned nucleophilic approaches. Linker et al. reported a short three-step synthesis of 2-C-branched glyco-amino acids by addition of nitroacetate to various glycals in the presence of ceric(IV) ammonium nitrate and subsequent reduction of the obtained bicyclic isoxazoline $\mathrm{N}$-oxides [106]. Caddick and coworkers used tetrafluorophenol-linked acrylate on solid phase for the synthesis of C1- and C6-linked glycopeptide mimetics [107]. The work represents the first $C$-glycoside synthesis on a solid phase using a free-radical methodology.

Radical allylation of acetobromomannose followed by ozonolysis gave a $C$-glycosyl aldehyde which was further elaborated into a $C$-mannosyl amino acid by Toone and coworkers [108]. This building block was incorporated into C-linked glycopeptides that acted as mono- and bivalent ligands for the legume lectin concanavalin A. Binding studies on resin beads and in solution were carried out to investigate the effect of carbohydrate presentation on the carbohydrate-lectin interaction. C-Linked glycopeptides have been used before by the group and evaluated as ligands for the Shiga-like toxin 1 binding subunit [109].

Dondoni et al. used $C$-glycosyl nitrile oxides and acetylenes for 1,3-dipolar cycloadditions to an alkyne or an azide, respectively, to obtain rigidified heterocycle-tethered $C$-glycosyl amino acids [110]. The isoxazole- or triazoletethered $C$-glucosyl and $C$-galactosyl alanines are promising building blocks for new glycopeptide mimetics. At the same time, Rutjes and coworkers also reported the synthesis of triazole-linked $C$-glycosyl amino acids employing 1,3-dipolar cycloadditions (cf. Sect. 3.2) [61].

The cross-metathesis (CM) reaction, being an important method for the preparation of diverse neoglycoconjugates [111], was used by Roy and coworkers for the conversion of $\beta$-C-allyl mannoside 77 and $(R / S)$ allyl glycine 78 into C-mannosylated amino acid 79 using Grubbs' catalyst (Scheme 16a) [112]. Earlier, the group had already applied CM in the synthesis of C-glycosylated peptoids [52] which have also been reported by Kessler and coworkers [113]. In $2002 \mathrm{McGarvey}$ et al. used this methodology for the reaction of $\alpha$-C-allyl glycosides from $N$-acetylglucosamine and lactose with protected allyl glycine derivatives, leading to the corresponding unsaturated $C$-glycosyl amino acid building blocks [114]. In a convergent approach, the reaction was also applied for the modification of an allyl- 
a)
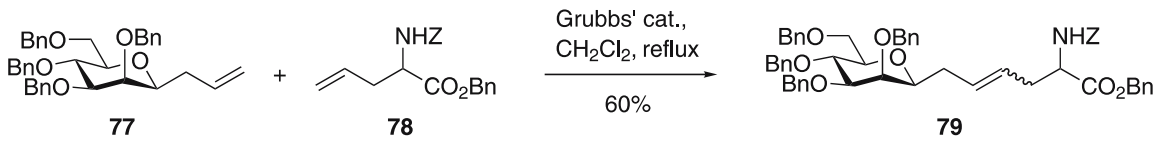

b)

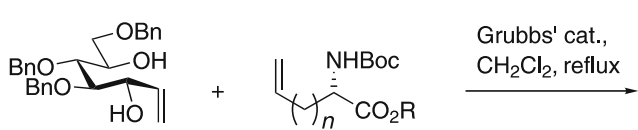

80
81

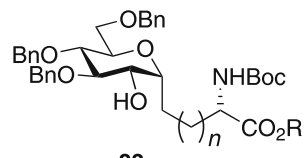

83

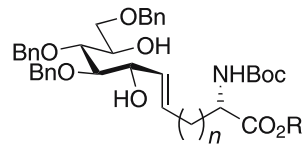

82

$$
n=0,1
$$

$\mathrm{R}=\mathrm{Bn}, \mathrm{Me}$

2. $\mathrm{BEt}_{3}, \mathrm{NaBH}_{4}$

Scheme 16 Applications of cross-metathesis (CM) for the preparation of C-glycosylated amino acids $\mathbf{7 9}$ (a) and $\mathbf{8 3}$ (b)

glycine-containing tripeptide. Liu and Ben applied CM for the preparation of a series of C-linked antifreeze glycoprotein analogues [115]. Another type of C-linked antifreeze glycoprotein analogue was reported earlier by the same group [116,117]. Nolen et al. used open-chain sugar precursor $\mathbf{8 0}$ for the preparation of C-glucosylated amino acids 83 with a linking carbon chain between the $C$-glycoside and the amino acid shorter than three carbons (Scheme 16b) [118]. Their CM/cyclization strategy provides a stereoselective entry to $C$-glucosyl alanines $83(n=0)$ and $C$-glucosyl analogues of glucosyl serines $\mathbf{8 3}(n=1)$, without the seriously diminished yields previously observed using allyl or vinyl $C$-glycosides.

Michael and coworkers employed aminomethyl- $C$-glycosides in a photochemical approach towards unnatural $C$-glycosyl asparagine derivatives [119, 120]. The products could be obtained by phototransamidation of the aminomethyl- $C$-glycosides with photoreactive asparagine derivatives under neutral conditions. Conformationally constrained $C$-glycosyl $\alpha$-and $\beta$-amino acids via Diels-Alder reaction have been reported by Jayakanthan and Vankar [121].

\section{4}

\section{Convergent Approaches to Glycopeptide and Glycoprotein Mimetics}

Compared to linear approaches, the convergent synthesis of glycopeptide and glycoprotein mimetics offers greater flexibility with respect to the sugars at- 
tached to a peptide. Thus, the preparation of several well-defined glycoforms of the same peptide/protein becomes possible. The approach is also of interest for combinatorial glycopeptide synthesis. If chemoselective ligation reactions are employed for the sugar attachment, it is possible to modify unprotected peptides and even whole proteins.

\section{1 \\ Formation of $\mathrm{C}=\mathrm{N}$ Bonds}

In 1996 Mutter et al. reported oxime formation as a means to chemoselectively couple reducing oligosaccharides to aminooxy-functionalized peptides [122]. Since then, oxime formation and related $\mathrm{C}=\mathrm{N}$ bond formations have been widely used to link carbohydrates and peptides with either the carbohydrate or the peptide acting as the carbonyl component. The possibility of using water as solvent and the high chemoselectivity of the reaction, making the use of protecting groups superfluous, are essential advantages of this methodology, which has also been applied in analytical chemistry [123]. However, one has to keep in mind that the reaction is potentially reversible.

Mimetics of $O$-glycopeptides with native sugar-peptide linkages were obtained by Bertozzi and coworkers [124]. A synthetic O-glycopeptide with a single $\mathrm{N}$-acetylgalactosamine residue was oxidized by galactose oxidase and the obtained GalNAc C- 6 aldehyde was reacted with several aminooxysubstituted carbohydrates. Later Bertozzi et al. applied aminooxylated carbohydrates for a chemoselective ligation with (2S)-aminolevulinic acidcontaining peptides prepared by SPPS to obtain glycopeptide mimetic $\mathbf{8 4}$ (Fig. 3) [125]. Similarly, hydrazide- and thiosemicarbazide-modified sugars were used to prepare the corresponding hydrazones and thiosemicarbazones, respectively. Wong and Schultz and their coworkers incorporated $p$-acetyl-L-phenylalanine into the $\mathrm{Z}$ domain of staphylococcal protein $\mathrm{A}$ by a genetic approach in response to the amber nonsense codon [126] according to a method established earlier $[127,128]$. Aminooxy-functionalized mono- and oligosaccharides were ligated and in part further elongated by glycosyltransferase-catalyzed glycosylations. The relatively low mass of the obtained glycoprotein mimetic 85 (approx. $8 \mathrm{kD}$ ) facilitated high-accuracy

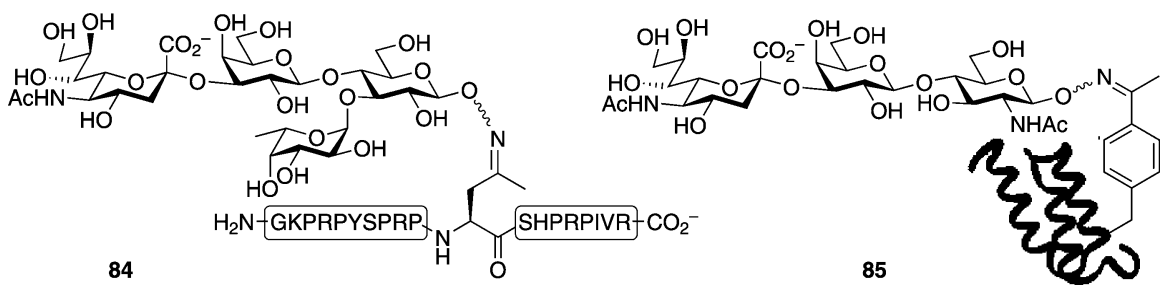

Fig. 3 Glycopeptide and glycoprotein mimetics obtained by oxime ligation 
mass spectrometry and thus a good control of the selective attachment of the unprotected aminooxy-modified saccharides.

In a series of papers, the Dumy group explored cyclic peptides with regioselectively addressable side-chain amino groups for the tetravalent presentation of mono- and disaccharides [129-132]. Recently, they reported the synthesis of a cyclic peptide template with two separated addressable domains (Scheme 17) [131]. Four Boc-protected lysine residues were used for the tetravalent attachment of carbohydrates. Two lysines orthogonally protected by Aloc groups served for attachment of molecular probes. Thus, $\mathbf{8 6}$ was first treated with a $\operatorname{Pd}(0)$ catalyst and phenylsilane to remove the Aloc groups, followed by attachment of a biotin and a fluorescein residue, respectively. TFA treatment and coupling of pentafluorophenyl (Pfp) ester 87 under basic conditions gave tetra keto-substituted peptides 88 and 89, re-
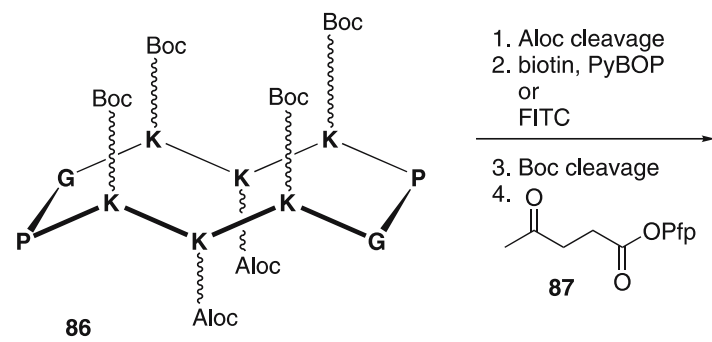

86

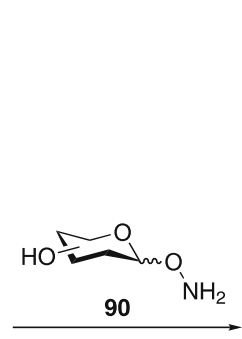

aq. buffer $\mathrm{pH} 4.0$

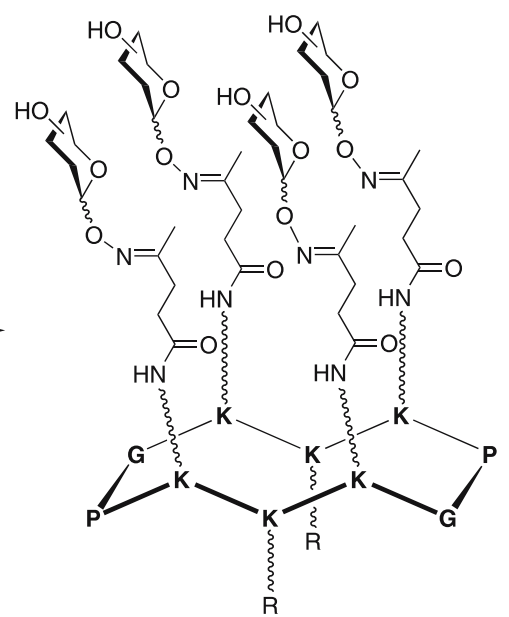

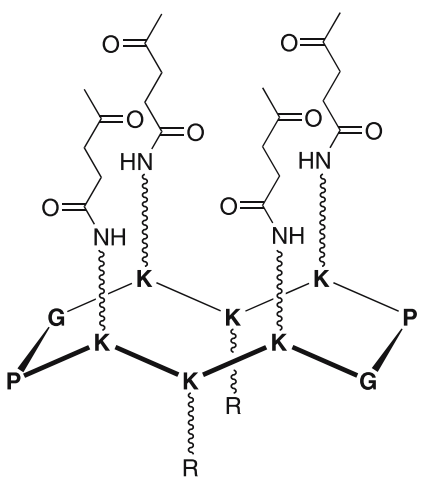

88: $R=$ biotin

89: $R$ = fluorescein
91: $\mathrm{R}$ = biotin

92: $R$ = fluorescein

Scheme 17 Application of the cyclic peptide template 86 with two separated addressable domains for the preparation of labeled neoglycopeptides $\mathbf{9 1}$ and $\mathbf{9 2}$ 
spectively. Oxime formation was achieved with several $\alpha$ - and $\beta$-configurated aminooxylated monosaccharides 90 under aqueous conditions. The obtained cyclic neoglycopeptides 91 and 92 were obtained in yields of $40-60 \%$ for the oxime formation step after RP-HPLC purification. Similar compounds have been used in lectin-binding studies [129, 132].

A chemoselective approach toward the sensitive detection of $O$-GlcNAc posttranslational modifications was developed by Hsieh-Wilson and coworkers [133]. Employing a modified UDP-Gal analogue with an acetylmethyl group replacing the $2-\mathrm{OH}$ group and a genetically engineered galactosyltransferase it was possible to label $O$-GlcNAc-modified proteins with a ketone tag. Oxime ligation with an aminooxy-substituted biotin derivative permitted the identification of several low-abundance $O$-GlcNAc-modified proteins from brain [134]. Ketone isosteres of GlcNAc and GalNAc have also been incorporated into the glycan chains of cell-surface glycoproteins by metabolic oligosaccharide engineering and identified by hydrazone ligation with biotin hydrazide [135].

Nicotra and coworkers applied oxime ligation to the covalent attachment of the $C$-glycoside analogue $\mathbf{9 4}$ of the Tn epitope to $\mathrm{T}$ cell epitope peptides, such as $\mathbf{9 3}$ modified with two aminooxy acetic acid residues (Scheme 18) [136-139]. The obtained neoglycopeptide 95, bearing two $\mathrm{B}$-epitopes and one T-epitope, could be presented to and recognized by the
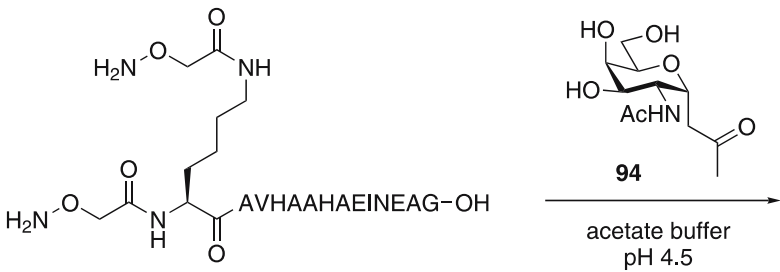

93

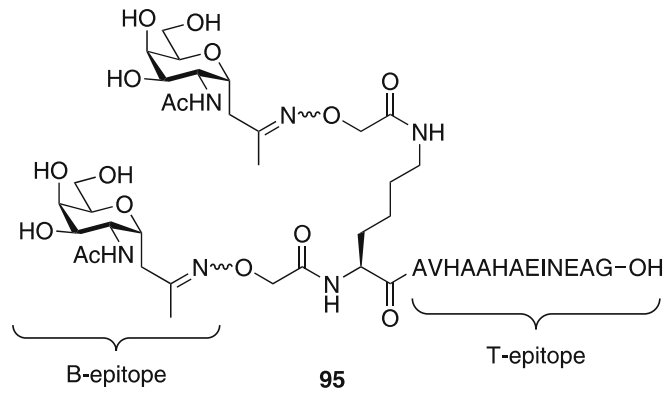

Scheme 18 Ligation of $C$-glycosyl ketone 94 to aminooxy-substituted T cell epitope peptide 93 
$\mathrm{T}$ cell receptor with higher efficiency than related neoglycopeptides having only one B-epitope.

A number of papers describe the use of aminooxy-modified peptides for the preparation of glycopeptide mimetics by chemoselective ligation to unmodified reducing mono- and oligosaccharides. The advantage of this approach is that oligosaccharides isolated from natural sources (e.g., from chemical or enzymatic degradation of glycoconjugates) can directly be used for conjugation to a peptide. Imperiali et al. used this approach to obtain several glycopeptide mimetics containing single GlcNAc residues as inhibitors of oligosaccharyl transferase [140,141]. Besides aminooxy-modified peptides, peptides with aspartic acid hydrazide were also employed. A problem associated with oxime and acyl hydrazone formation is the fact that the ligation products can exist in two forms, cyclic and acyclic, and each of them as several diastereoisomers (Scheme 19). It has been reported that the acyclic form dominates in the case of ligations with alkoxyamines (Scheme 19a) $[142,143]$ whereas the cyclic form is preferred with hydrazides (Scheme 19b) [143-147]. The product ratio, however, is dependent on the carbohydrate. In order to fix the sugar in a defined acyclic form, subsequent reduction with, e.g., sodium cyanoborohydride to give the corresponding hydroxylamine and hydrazide, respectively, may be carried out. This process, however, generates new nucleophilic centers (which might have additional utility [148]) and is no longer a sheer ligation reaction.

a)

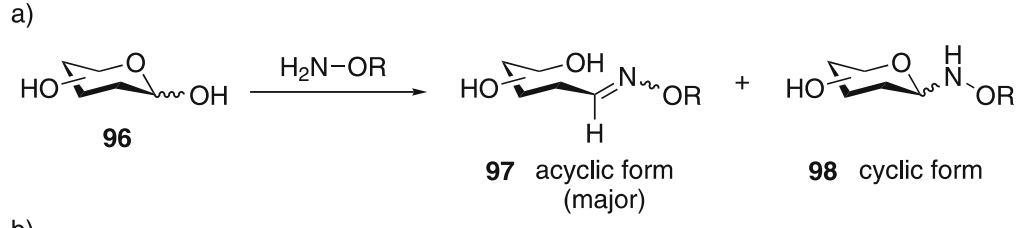

b)

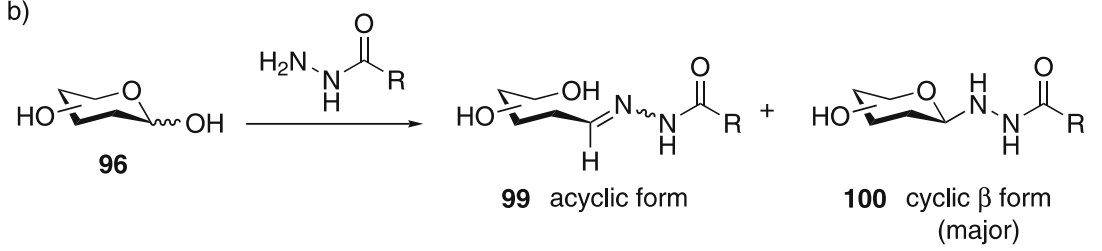

Scheme 19 Oxime (a) and acyl hydrazone (b) formation leads to mixtures of acyclic and cyclic ligation products

As an alternative strategy, the use of $\mathrm{N}, \mathrm{O}$-disubstituted hydroxylamines has been described [149]. In contrast to oxime formation, the cyclic nature of the saccharide reducing unit is completely preserved. The reaction also proceeds with high stereoselectivity to give under thermodynamic control the $\beta$ or $\alpha$ pyranose forms depending on the sugar. Carrasco et al. followed this approach and prepared differently protected amino acids with 
a methyl aminooxy group and a methoxyamino group, respectively, in their side chain [150-152]. SPPS following the Boc strategy gave unprotected peptides 101-104 that were chemoselectively glycosylated to generate neoglycopeptides 105-107 (Scheme 20). The ligation yields were in the range of 75\% and more. Glycosylation with the sterically hindered threonine derivate 104, however, failed. The same strategy was successfully applied by Rocchi et al. for the synthesis of opioid deltorphin I analogues [153].
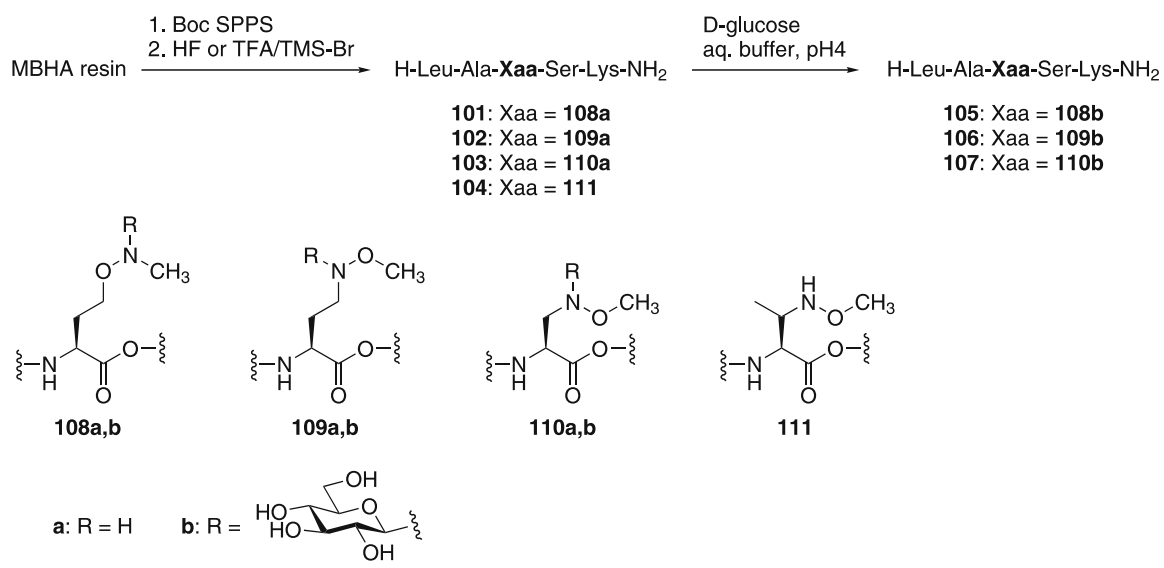

Scheme 20 Peptides containing N,O-disubstituted hydroxylamines and their use in chemoselective ligation reactions with unprotected glucose

Aminooxy- and methylaminooxy-substituted homoalanines were incorporated into T4 phage lysozyme and streptavidin by Nishimura and coworkers [154] employing the frameshift suppression strategy on the basis of the four-base codon/anticodon system [155]. Chemoselective coupling between the methylaminooxy-containing mutant streptavidin and unmodified mono-, di-, and trisaccharides allowed for the combinatorial synthesis of several glycoprotein mimetics.

\section{2 \\ Formation of $\mathbf{C}-\mathbf{N}$ Bonds}

Arya and coworkers developed automated, multistep, solid-phase strategies for the parallel synthesis of libraries of carbon-linked glycopeptide mimetics, such as 116-118 (Scheme 21) [156-158]. Starting from solid-phase bound peptide 112, a $C$-glycosyl aldehyde 113 was attached by reductive amination followed by amide bond formation using $C$-glycosyl carboxylic acid derivatives 115 to result in neoglycopeptides 116. Using this approach, a variety of $\alpha$ - or $\beta$-carbon linked carbohydrates can be incorporated either at the N-terminus or at internal nitrogens of short peptides in a highly flex- 

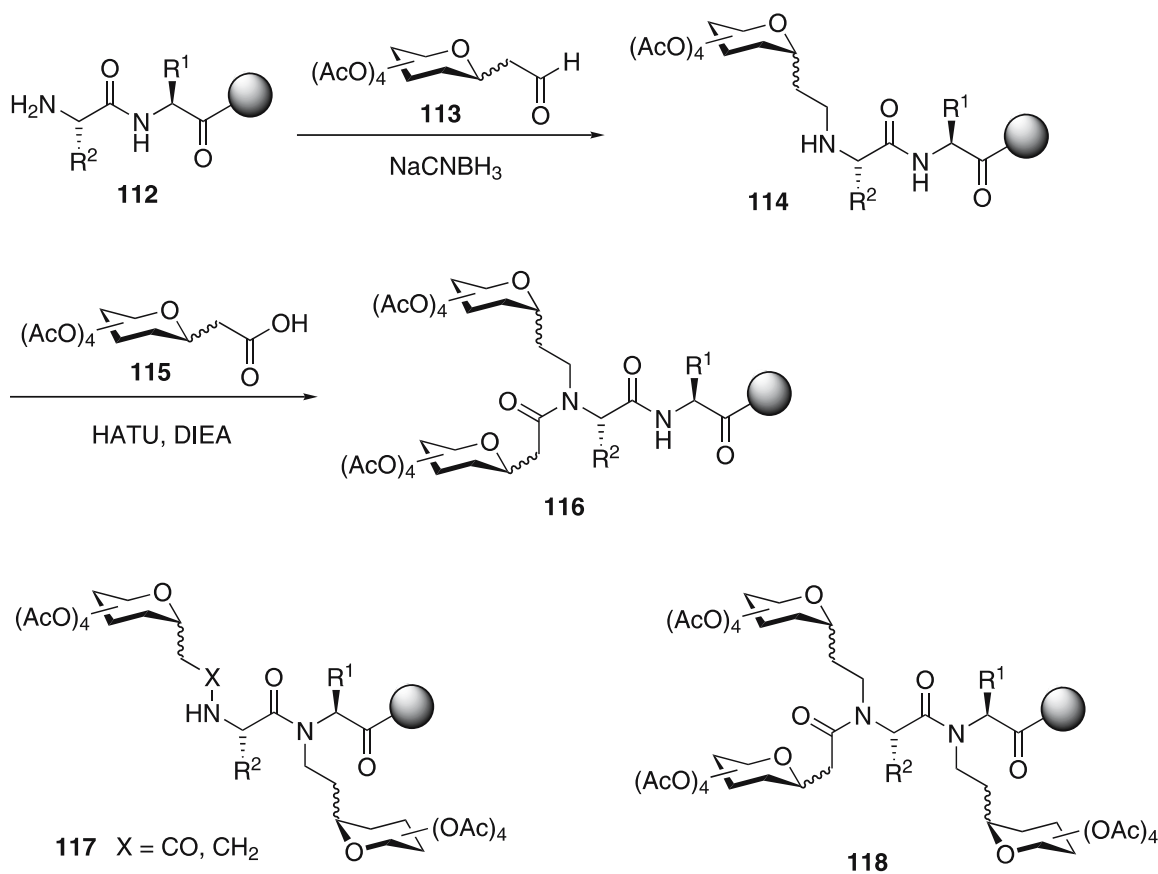

Scheme 21 Strategy for the combinatorial synthesis of carbon-linked glycopeptide mimetics 116. Structures 117 and 118 may be obtained analogously

ible manner. The glycopeptide mimetics were used as probes for studying carbohydrate-protein interactions as well as protein folding and trafficking.

Wang and coworkers established a general method for rapid generation and screening of a combinatorial $C$-glycopeptide library in the one-bead onecompound format [159]. An $\alpha$-C-galactosyl carboxylic acid derivative 115 was activated as a pentafluorophenyl ester and coupled to the $\mathrm{N}$-terminus of the peptides under standard solid-phase conditions. Partial termination during peptide synthesis (ladder synthesis $[160,161]$ ) allowed for mass spectrometric identification of lead structures bound to single beads. Several glycopeptide sequences mimicking the $\mathrm{Gal}(\alpha-1,3) \mathrm{Gal}$ epitope in binding to human natural anti-Gal antibodies were identified.

Wittmann and coworkers reported the convergent solid-phase synthesis of multivalent cyclic neoglycopeptides to study the influence of carbohydrate presentation on the binding affinity to lectins (Scheme 22) [162,163]. Starting from library 119 of linear nonapeptides, side-chain cyclization was achieved by $\operatorname{Pd}(0)$-catalyzed removal of the Aloc and allyl groups followed by HBTU/HOBt activation. Hydrazine treatment liberated Ddvprotected ( $\mathrm{Ddv}=1$-(4,4-dimethyl-2,6-dioxocyclohexylidene)isovaleryl) sidechain amino groups of the cyclic peptides. For the attachment of carbohydrates a new linker based on the Aloc protecting group has been developed. 

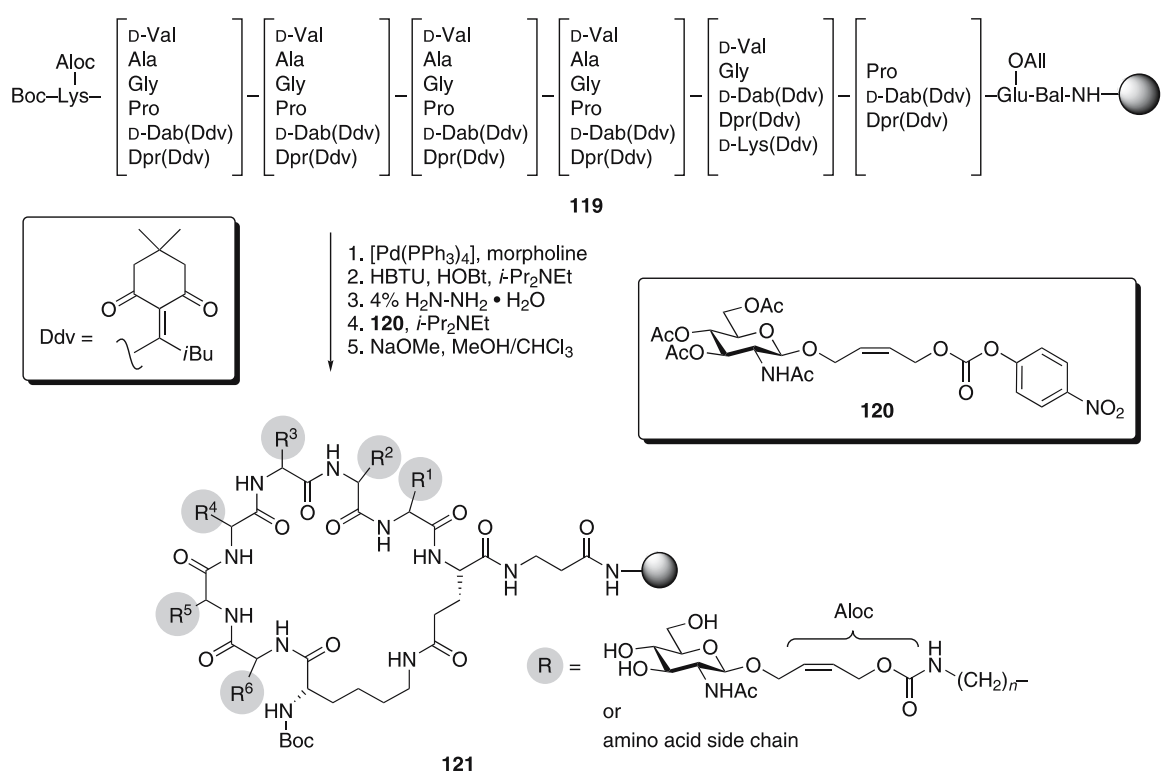

Scheme 22 Preparation of library 121 of 19440 conformationally restricted glycoclusters for the spatial screening of multivalent lectin ligands

Thus, treatment with activated carbonate 120 led to urethane formation in virtually quantitative yields. The obtained combinatorial one-bead onecompound library 121 of 19440 conformationally restricted, spatially diverse glycoclusters has been screened for binding to wheat germ agglutinin (WGA) by a solid-phase enzyme-immuno lectin-binding assay. Several tetra-, penta-, and hexavalent high-affinity ligands were identified by single-bead Edman degradation after palladium-catalyzed detachment of the sugars according to a strategy described earlier [164]. It was concluded that the spatial presentation of the sugars on the cyclopeptide scaffolds is responsible for the high affinity to WGA.

Cyclic peptides as scaffolds for the attachment of carbohydrates have also been reported by Nishimura et al. [165]. Aminohexyl-spacer modified disaccharides were coupled to glutamine side chains by a reaction catalyzed by transglutaminase according to a method described by Klaffke et al. [63] and further elongated by an $\alpha-2,3-(N)$-sialyltransferase-catalyzed glycosylation. The obtained trivalent glycopeptide mimetics displayed different binding affinity to influenza hemagglutinin depending on the peptide conformation. For the best ligand, a tridentate glycopeptide-protein complex was suggested, based on computer calculations.

Finn and coworkers described the use of whole icosahedral cowpea mosaic virus particles as multivalent carbohydrate display platforms [166]. When treated with $\alpha$-D-mannopyranosyl-phenylisothiocyanate, up to 120 mannose 
residues were attached to lysine residues on the virus surface by thiourea formation. Aggregation of labeled virus with the plant lectin concanavalin A was studied by UV/VIS spectroscopy, transmission electron microscopy, and fluorescence resonance energy transfer. The nature of this multivalent interaction was shown to depend upon the density and position of functionalization of the virus. Modification of adenovirus (AV) lysine residues by 2-imino-2methoxyethyl-1-thioglycosides was used by Davis and coworkers to modulate the ability of AV to function as gene delivery vector [167]. It was possible to "switch off" AV transfection by the normal receptor pathway and "switch on" a specific sugar-mediated pathway. The same imidate chemistry which had originally been developed by Lee and coworkers for the preparation of neoglycoproteins [168] was applied by the Davis group to generate glycosylated forms of rhamnosidase for use in a bipartite drug-delivery system called lectin-directed enzyme-activated prodrug therapy (LEAPT) [169].

\section{3}

\section{Sulfur as Nucleophile}

\subsection{1}

\section{S-Alkylation}

The first report on the use of the reaction of glycosyl iodoacetamides with cysteine residues for the synthesis of N-linked glycoprotein mimetics came from the Flitsch group [170] and was later followed by a report on the modification of unprotected synthetic peptides containing a single cysteine residue in solution [171]. Dahmén and Kihlberg et al. coupled 2 -bromoethyl $\beta$-glycosides of galabiose [ $\mathrm{Gal}(\alpha 1-4) \mathrm{Gal}]$, globotriose [ $\mathrm{Gal}(\alpha 1-$ $4) \mathrm{Gal}(\beta 1-4) \mathrm{Glc}$ ], and $3^{\prime}$-sialyllactose [Neu5Ac$(\alpha 2-3) \mathrm{Gal}(\beta 1-4) \mathrm{Glc}$ ] to cysteine and homocysteine residues in T cell-stimulating peptides by cesium carbonate promoted alkylation in yields of 52-95\% [172]. Neither $\beta$-elimination nor epimerization of the neoglycopeptide stereocenters occurred. More recently, the iodoacetamide approach was applied by Flitsch and coworkers for the semi-synthesis of homogeneous glycoforms of human erythropoietin (EPO) [173]. Several mutants in which N-glycosylation site asparagines had been changed to cysteines were reacted with GlcNAc iodoacetamides in yields of about $50 \%$. This was possible even in the presence of additional cysteine residues involved in disulfide bridges. Purification was readily carried out by lectin affinity chromatography.

Glycosyl iodoacetamides may also be applied to solid-phase glycopeptide synthesis. This allows for selective modification of certain cysteine residues in peptides with several cysteines employing orthogonal protection. Macmillan and Flitsch and coworkers applied the 4-sulfamylbutyryl-AM (safety-catch) resin [174] to obtain neoglycopeptide thioesters derived from the first 28 amino acids of the glycoprotein hormone EPO (Scheme 23) [175]. Peptide 122 

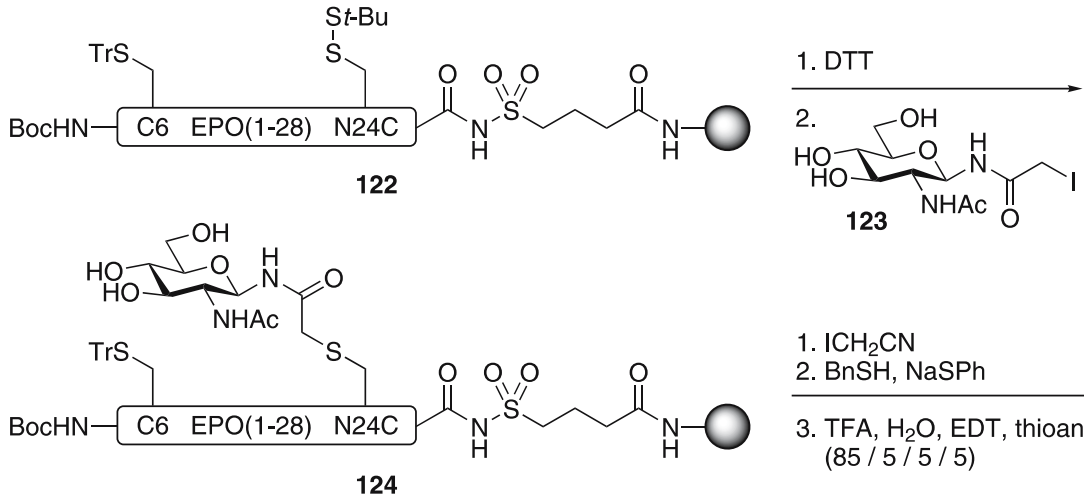

1. $\mathrm{ICH}_{2} \mathrm{CN}$

2. $\mathrm{BnSH}, \mathrm{NaSPh}$

3. TFA, $\mathrm{H}_{2} \mathrm{O}$, EDT, thioanisole $(85 / 5 / 5 / 5)$

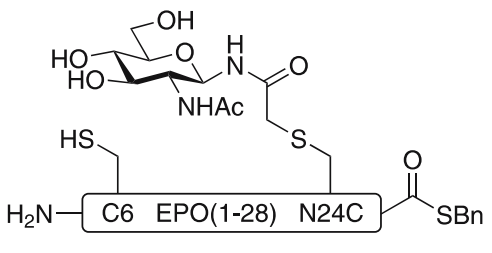

125

Scheme 23 Application of glycosyl iodoacetamide 123 to the solid phase synthesis of glycopeptide mimetic 125

was prepared by Fmoc SPPS and selectively deprotected by reduction with dithiothreitol (DTT). The free thiol was then alkylated with iodoacetamide 123 to give glycopeptide mimetic 124 . The glycopeptide was released from the resin with benzyl mercaptan in the presence of catalytic NaSPh after activation with iodoacetonitrile. Deprotection with concentrated TFA gave glycopeptide thioester 125. Later it was shown by Macmillan and Arham [176] that glycopeptide thioesters obtained by this approach are suitable for the synthesis of glycoproteins by native chemical ligation [177]. In the same year, a complex-type disialyl-undecasaccharide was appended to a cysteine residue of an undecapeptide using a bromoacetamidyl oligosaccharide [178]. It was shown that the obtained glycopeptide analogue was resistant to enzymatic digestion by peptide:N-glycosidase F (PNGase-F).

Bertozzi and coworkers adapted Flitsch's haloacetamide method to convergently ligate bromoacetamides of Gal and GlcNAc to a C-3 thiol of a GalNAc $(\alpha 1-\mathrm{O})$ Thr-containing peptide with natural carbohydrate-peptide linkage [179]. The obtained thioether-linked structures can be regarded as mimetics of "core 1" and "core 3" structures of mucin-type glycoproteins. Later the work was extended to the synthesis of thioether-linked analogues of the mucin-related 2,3-sialyl-TF and MECA-79 antigens [180] as well as to the synthesis of $\mathrm{N}$-linked glycopeptide mimetics that replace the glycosidic linkages extending from the core pentasaccharide with thioethers 

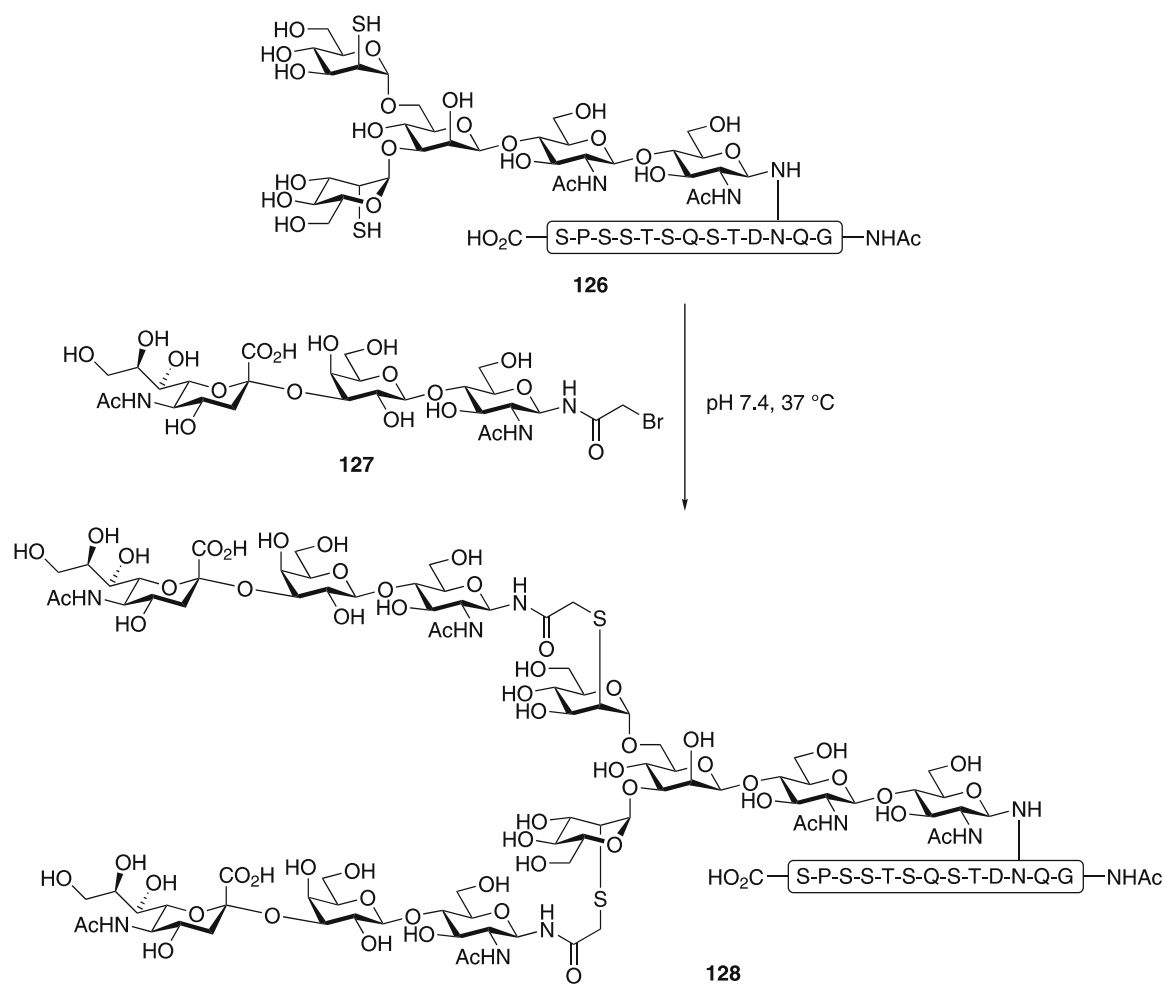

Scheme 24 Application of the haloacetamide ligation for the convergent assembly of neoglycopeptide 128 containing an undecasaccharide mimetic

(Scheme 24) [181]. A protected pentasaccharide-Asn analogue containing two thiol residues was incorporated into CD52 (a glycopeptide expressed on human lymphocytes and sperm cells) by Fmoc SPPS to give, after deprotection, 126. Undecasaccharide mimetic $\mathbf{1 2 8}$ was then readily generated by alkylation of 126 with bromoacetamido trisaccharide 127.

The application of 1-thiosugars for the preparation of S-glycosylated amino acid building blocks has already been discussed in Sect. 3.3. The approach, however, can also be carried out in a convergent manner. To this end, Zhu and Schmidt used O-acetyl protected 1-thio derivatives of GalNAc, GlcNAc, and lactose and attached them to $\beta$-bromoalanine- or $\gamma$-bromohomoalanine-containing di- to hexapeptides to give S-linked neoglycopeptides [75]. The reaction selectively gave $\alpha$ - and $\beta$-S-glycosides and even worked well with O-unprotected 1-thiosugars. Glycosylthiomethyl bromides and azides have also been applied in a convergent approach [82].

Aziridine-2-carboxylic acid (Azy)-containing peptides represent alternative electrophilic peptides for conjugation with thiols. Van der Donk and Gin and coworker prepared aziridine-containing peptide 132 starting from 

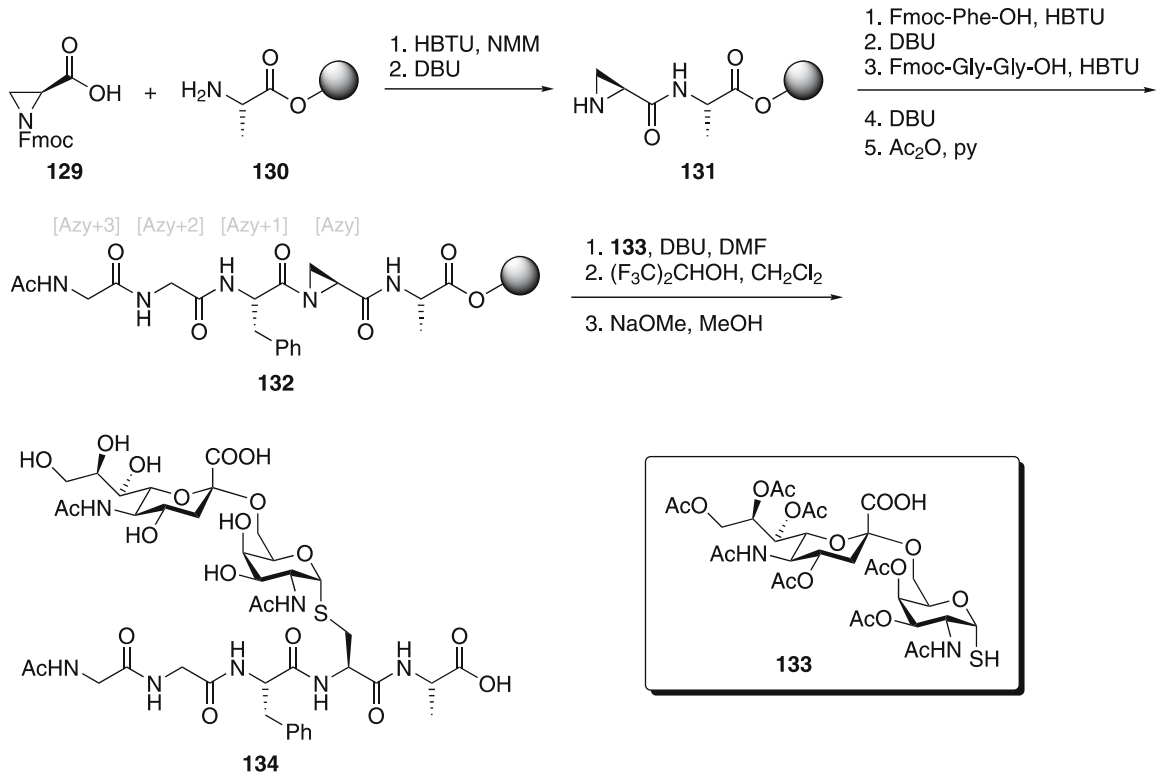

Scheme 25 Conjugation of 1-thio-disaccharide 133 to solid phase-bound Azy-containing peptide 132 leads to $S$-glycopeptide 134

Fmoc-Azy-OH 129 and solid phase bound alanine 130 (Scheme 25) [182]. Attempts to extend 131 by sequential coupling of single Fmoc-amino acids were unsuccessful, presumably due to intramolecular aziridine $\mathrm{N}$-deacylation by the liberated amine upon Fmoc removal at the $[\mathrm{Azy}+2]$ position (numbering according to the direction of the synthesis). This side reaction could be avoided by employing a dipeptide building block for coupling of the residues in the positions $[\mathrm{Azy}+2]$ and $[\mathrm{Azy}+3]$ leading to 132. Addition of 1-thiodisaccharide 133 and deprotection gave $S$-glycopeptide 134 containing the thio analogue of the sialyl Tn (STn) antigen. Similarly, other 1-thiosugars were conjugated. In all cases, base-promoted aziridine ring-opening occurred with high regioselectivity delivering only small amounts of the corresponding $\beta^{2}$-amino acid derivative.

\subsection{2}

\section{Conjugate Addition to Michael Acceptors}

The conjugate addition of thiols to maleimido moieties [183] has been widely used in bioconjugate chemistry [184]. Hansen and coworkers were the first to apply this reaction to the preparation of neoglycopeptides [185]. A reducing disaccharide was reacted with $S$-trityl-2-mercaptoethylamine and stabilized in the cyclic form by $\mathrm{N}$-acetylation. After detritylation, the thiolfunctionalized carbohydrate was coupled to maleimido-functionalized pep- 
tides to result in neoglycopeptides with a flexible linker between carbohydrate and peptide moieties.

Shin et al. synthesized maleimido-modified sugars for the chemoselective reaction with cysteine-containing peptides and proteins (Scheme 26) [186, 187]. Since deacetylation of $\mathbf{1 3 5}$ and similar sugars under mild basic conditions was not possible neither before nor after thiol ligation due to imide opening, TBS-protected sugars, such as 136, were employed giving access to 137. Alternatively, unprotected maleimido-modified sugars were obtained by a two-step procedure in $54-95 \%$ as shown for the conversion of 138 into 139. These sugars were successfully attached to glutathione ( $\gamma$-Glu-Cys-Gly), the synthetic Fas peptide 140, and to bovine serum albumin possessing a single reduced cysteine at position 58. Later, Shin et al. used thiol-maleimide ligation also for the fabrication of carbohydrate microarrays $[188,189]$.

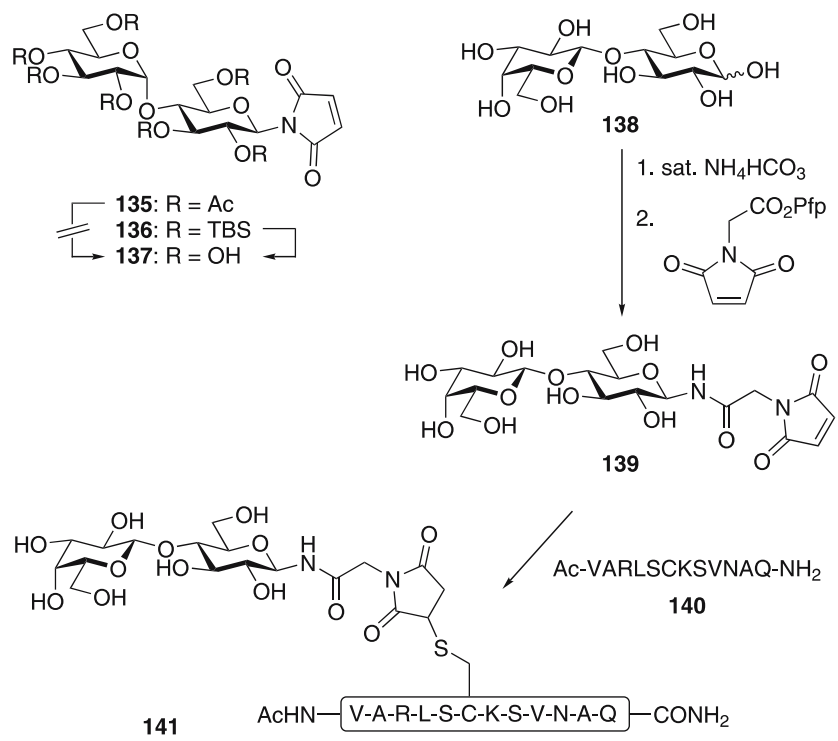

Scheme 26 Application of maleimido-modified sugars for the chemoselective ligation with cysteine-containing peptides

Van der Donk and coworkers used dehydroalanine-containing peptides for the chemoselective conjugate addition of glycosyl thiolates [190,191]. As the dehydroalanine precursor, Se-phenylselenocysteine was introduced via SPPS. Oxidative elimination of this precursor was effected by sodium periodate addition and provided the dehydropeptide. Subsequent ligation with different $\alpha$-glycosyl thiolates resulted in thio isosteres of the tumor-associated carbohydrate antigens $\mathrm{Tn}, \mathrm{T}, \mathrm{STn}$, and 2,6-ST in high yields. The process proceeded with complete retention of the $\alpha$-anomeric configuration. No stereoselectivity, however, was observed at the newly formed cysteine stereocenter. The 
incorporation of selenocysteine into peptides is not only of interest as a precursor for chemoselective modification of peptides but also for the preparation of larger peptides and proteins by selenocysteine-mediated native and expressed protein ligation [192].

\subsection{3 \\ Disulfide Bond Formation}

The modification of cysteine residues within proteins combined with sitedirected mutagenesis offers a strategy for site-selective incorporation of glycans into proteins. Beside the alkylation reactions discussed in Sects. 4.3.1 and 4.3.2, disulfide bond formation has been explored by several groups towards this goal. Boons et al. used 5-nitropyridine-2-sulfenyl activated thioglycosides for the preparation of disulfide-linked BSA-GlcNAc conjugates [193]. More recently, they reported the direct coupling of 1-thiosugars (thioaldoses) with the thiol group of free cysteine-containing peptides and proteins due to difficulties encountered in synthesizing nitropyridinesulfenyl thioglycosides of oligosaccharides [194]. A number of thioaldoses derived from several oligosaccharides including the core pentasaccharide of $\mathrm{N}$-glycoproteins were synthesized. Incubation of 1-2 equivalents of 1-thio-chitobiose with cysteinecontaining glutathione and BSA resulted in the site-specific formation of the disulfide-linked neoglycoconjugates together with the homodisulfides of glutathione and BSA in statistical amounts. The same technology was applied to the "glycosylation" of an aglycosylated human IgG1-Fc antibody fragment, engineered to have Cys-297 in place of glycan-linked Asn [195]. Mass spectrometry analysis verified site-selective and complete saccharide incorporation without affecting other Fc protein disulfides. The neoglycoproteins displayed enhanced inhibition of superoxide production by $\gamma$-interferonstimulated U937 cells relative to the aglycosylated N297C protein, where increased glycan size correlated positively with increased inhibition.

Davis et al. reported a whole series of carbohydrate derivatives suitable for chemoselective, cysteine-specific synthesis of neoglycoproteins (Scheme 27) [196-202]. Methanthiosulfonates bound to carbohydrates either via a linker (142) or directly (143) (glyco-MTS derivatives) react specifically with thiols of cysteine-containing proteins 146 and allow the specific synthesis of disulfide-linked glycoproteins 147 in high yields [196-198]. This was demonstrated by site-selective conjugation of glyco-MTS derivatives to cysteine mutants of the serine protease subtilisin Bacillus lentus (SBL), which does not naturally contain cysteine. A library of 48 glycosylated forms of SBL as single, pure species has been prepared and detailed glycan structurehydrolytic activity relationships have been determined. The efficiency of the approach of disulfide bond formation using glyco-MTS derivatives was later improved by using glycosyl phenylthiosulfonates (glyco-PTS) 144 [199]. In most cases these reagents gave superior yields of neoglycoproteins 147. 

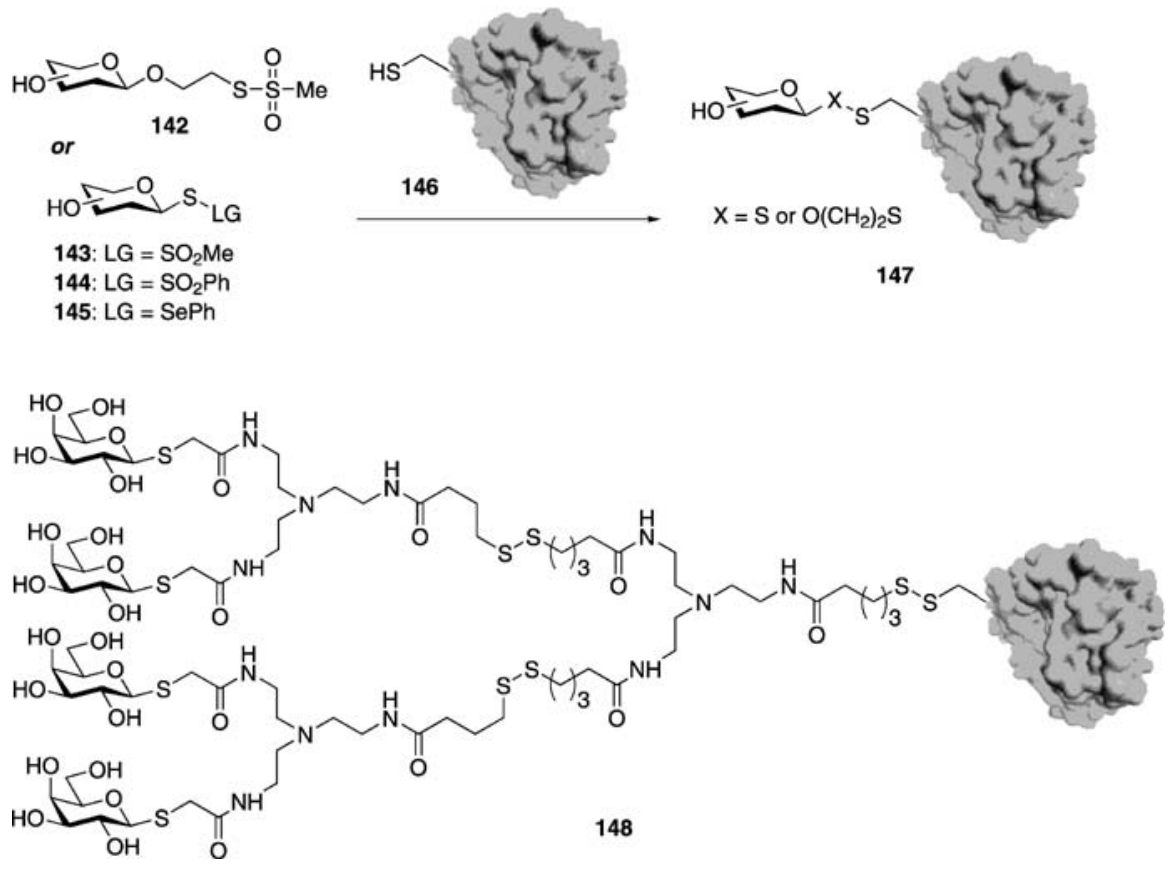

Scheme 27 Glyco-MTS (142, 143), glyco-PTS (144), and glycosyl selenenylsulfide (145) derivatives developed for the synthesis of neoglycoproteins 147 and glycodendriproteins, such as 148

The glyco-MTS strategy has also been used for the attachment of different bi- and tetravalent glycodendrimers to the Ser156Cys mutant of SBL to give so-called glycodendriproteins, such as 148 [200, 201]. These galactosepresenting synthetic glycoprotein mimetics turned out to be nanomolar inhibitors of the co-aggregation of the pathogen Actinomyces naeslundii with co-pathogen Streptococcus oralis. It was shown that both the multivalent presentation of galactose and the protein degrading activity of this SBL neoglycoconjugate are essential for optimal inhibition.

Recently, Davis and coworkers described selenenylsulfide-mediated glycoconjugation as a new strategy for the synthesis of disulfide-linked glycoproteins $147(X=S)$ [202]. Two alternative routes were studied. Either a 1-thio mono- or oligosaccharide was converted into the glycosyl selenenylsulfide 145 and then reacted with a cysteine-containing protein 146 or the protein was first converted into the corresponding (phenylselenenyl)sulfide by treatment with phenylselenenyl bromide and then reacted with 1-thio mono- or oligosaccharides. With this approach it was possible to prepare neoglycoproteins from several model proteins modified with mono- and oligosaccharides of up to seven saccharide units. 
The formation of disulfides under conditions allowing thiol/disulfide exchange can be used for the preparation of dynamic combinatorial libraries (DCLs) [203-206]. First applications of DCLs in carbohydrate chemistry were reported by Sasaki et al. [207] and Lehn et al. [208, 209]. Sando and Aoyama and coworker prepared DCLs of glycopeptide mimetics based on disulfidelinked sugar-peptide coupling [210]. A mixture of 1-thiogalactose and two peptides containing two cysteine residues each afforded in the presence of DTT a disulfide library of at least ten sugar-peptide conjugates and cyclic peptides. Preliminary surface plasmon resonance experiments showed that the library contained active divalent galactoside species capable of cross-linking soluble peanut lectin (PNL) to PNL immobilized on the sensor-chip surface.

A similar approach was applied by Davis et al. [211]. They used their selenenylsulfide-mediated glycoconjugation approach for the preparation of several disulfide-linked glycopeptide mimetics containing glucose and GlcNAc and observed the composition of the library under conditions allowing thiol/disulfide exchange. Upon addition of wheat germ agglutinin, a GlcNAcbinding plant lectin, an enrichment of GlcNAc-containing glycopeptides was observed.

\section{4}

\section{Azide-Alkyne [3 + 2] Cycloaddition}

The copper(I)-catalyzed azide-alkyne cycloaddition $[58,59]$ represents a mild method for the regioselective preparation of 1,4-disubstituted 1,2,3-triazoles even in a biological environment and is now widely used in bioconjugate chemistry [60]. In their seminal paper, Meldal et al. applied this reaction to the synthesis of unnaturally linked glycopeptides [58]. 2-Azidothiogalactoside $\mathbf{1 5 0}$ was reacted in the presence of two equivalents of copper(I) iodide with solid-phase bound peptides substituted with a terminal alkyne group either at the peptide backbone or at the amino-acid side chain, as shown for propargylglycine derivative $\mathbf{1 4 9}$ (Scheme 28). The reactions gen-

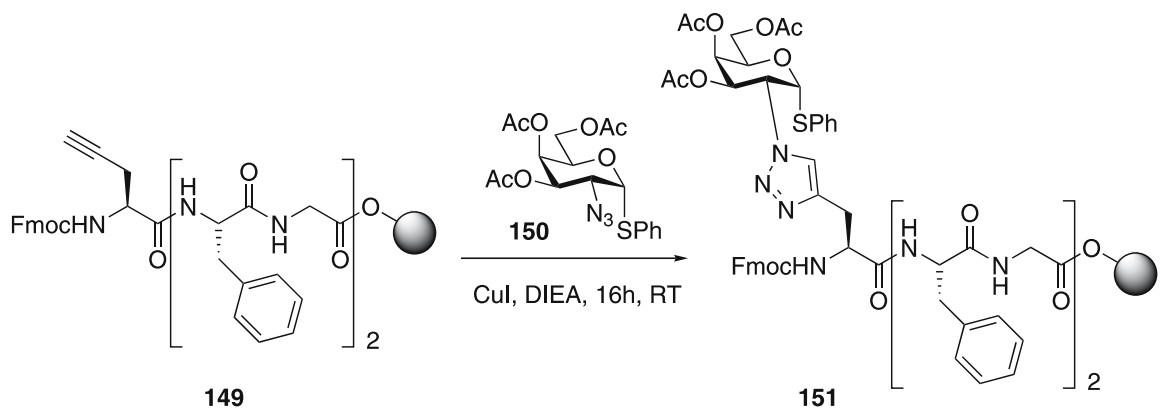

Scheme 28 Copper(I)-catalyzed azide-alkyne cycloaddition for the solid-phase synthesis of triazole-linked glycopeptide mimetics 
erally worked with $>95 \%$ conversion and $>95 \%$ purity $(78 \%$ purity in the case of 151).

Lin and Walsh applied the copper(I)-catalyzed azide-alkyne cycloaddition for the attachment of 21 different azido-functionalized monosaccharides to 13 derivatives of the cyclic decapeptide tyrocidine with one to three propargylglycine residues incorporated at positions 3-8 [212]. Head-to-tail cyclization of the peptides was accomplished using a thioesterase domain from tyrocidine synthetase. Antibacterial and hemolytic assays showed that the two best glycopeptide mimetics had a sixfold better therapeutic index than the natural tyrocidine.

It has been shown that alkyne- and azido-modified amino acids, such as 2-amino-5-hexynoic acid [213], azidohomoalanine [214,215], and with less efficiency also azidoalanine, azidonorvaline, and azidonorleucine [216], act as methionine surrogates that are activated by the methionyl-tRNA syn-

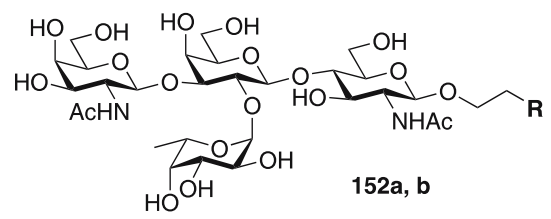

152a, 153a: $R=N_{3}$

152b, 153b: $R=$

$\overbrace{\mathrm{OH}}^{\mathrm{OH}}$
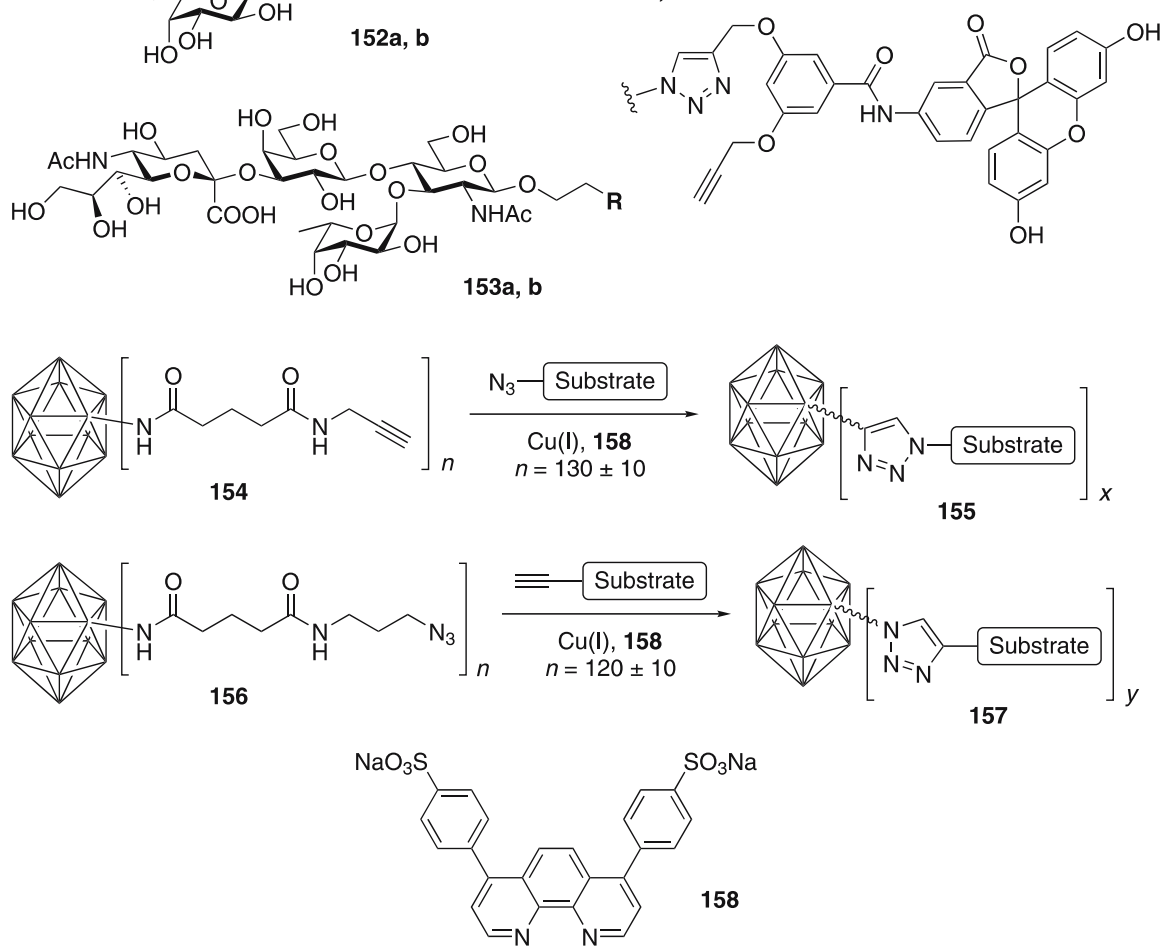

Scheme 29 Application of the copper(I)-catalyzed azide-alkyne cycloaddition for the preparation of glycoviruses 
thetase of E. coli and replace methionine in proteins expressed in methioninedepleted bacterial cultures. This, together with other methods for the incorporation of non-canonical amino acids into proteins [41,217], offers the possibility to use azide-alkyne cycloaddition (and also Staudinger ligation [218-220]) not only for protein labeling within cells or on cell surfaces $[215,216]$ but also for the preparation of glycoprotein mimetics.

Based on work carried out earlier by the same group [221], Finn and coworkers succeeded in the attachment of more than 100 copies of the two complex tetrasaccharides $\mathbf{1 5 2}$ and $\mathbf{1 5 3}$ to the cowpea mosaic virus (CPMV) (Scheme 29) [222]. To allow for ready quantification of the conjugation, the sugar azides 152a and 153a were first converted into fluorescein-labeled compounds $152 \mathrm{~b}$ and $153 \mathrm{~b}$ by azide-alkyne cycloaddition to the corresponding fluorescein dialkyne. In a second step, dye alkyne derivatives $152 \mathrm{~b}$ and $153 \mathrm{~b}$ were grafted to CPMV azide 156 to give 157 with loadings of 115 and 105 per virion, respectively. Likewise, attachment of sugar azides 152a and 153a to alkyne-modified CPMV 154 under similar conditions gave glycoviruses 155 , assuming the same reactivity as with the fluorescein-tagged sugars. The unfortunate tendency of copper ions to accelerate the hydrolytic cleavage of peptide bonds was suppressed by the use of an excess of the sulfonated copper ligand bathophenanthroline $\mathbf{1 5 8}$ to restrict accessibility of the metal center.

\section{5 \\ Metabolic Oligosaccharide Engineering and Subsequent Bioorthogonal Ligation}

Metabolic oligosaccharide engineering offers the possibility of using the cell's biosynthetic machinery to introduce carbohydrates with unnatural structural elements into the glycan chains of glycoproteins in cell culture and in animals. Reutter and coworkers have demonstrated that mannosamine derivatives, in which the $\mathrm{N}$-acetyl group of ManNAc was substituted with for example $\mathrm{N}$-propanoyl, $\mathrm{N}$-butanoyl, or $\mathrm{N}$-pentanoyl groups, can be taken up by cells and are converted into the corresponding sialosides. These are incorporated into sialoglycoconjugates, replacing in a cell-type specific manner $10-85 \%$ of normal sialic acids [223-225]. Application of this approach to different biological systems revealed important and unexpected functions of the $\mathrm{N}$-acyl side chain of sialic acids. Sialic acids modified in such a way led, for example, to markedly altered binding and/or infection of different primate polyoma viruses that depend on cell surface sialic acids for entry. Both inhibition (over 95\%) and enhancement (up to sevenfold) of virus binding and infection were observed, depending on the modification [224].

The promiscuity of the sialic acid biosynthetic pathway has been exploited by Bertozzi et al. to introduce ketone [226] and azide groups [218] into cell surface sialoglycoconjugates. Due to their unique chemical reactivity, these groups can be used for attachment of chemical probes through bioorthogonal 
coupling reactions. The versatility of this technology was demonstrated by an example of selective drug delivery [226]. Several human cell lines were treated with $\mathrm{N}$-levulinoylmannosamine (ManLev). Ketone-containing cell surface glycans were conjugated to biotinamidocaproyl hydrazide through the formation of an acyl hydrazone to provide a tag for subsequent detection with fluorescein-labeled avidin or for delivery of a ricin A chain-avidin conjugate. Ricin toxin A chain is a potent inhibitor of protein synthesis. At certain concentrations, the ricin A chain-avidin conjugate showed selective toxicity for cells treated with ManLev.

Later, Bertozzi et al. developed an improved bioorthogonal ligation reaction based on a modified Staudinger reaction [218,219]. This so-called Staudinger ligation allows a selective reaction between azides and modified triphenylphosphines containing an intramolecular electrophilic trap leading to formation of an amide bond (Scheme 30). The azide and phosphine are both abiotic and essentially unreactive toward cellular biomolecules. Since $\mathrm{N}$-azidoacetylmannosamine (ManNAz) 159 is metabolized by cells and incorporated into surface glycoconjugates 160 , the Staudinger ligation can be used with labeled triarylphosphines 161 to produce stable cell-surface adducts $\mathbf{1 6 2}$. Recently, Bertozzi et al. could show that the Staudinger ligation can also be executed in living animals [227]. The process of cell surface engineering offers a variety of applications including the generation of artificial cellular receptors for drug targeting, viral gene delivery, and diagnostics, the improvement of glycoprotein properties, and the attachment of labels to study the behavior of glycoproteins in vivo $[225,228,229]$. The metabolic labeling approach can also been used for proteomic analysis of mucin-type O-linked glycoproteins [230] and $O$-GlcNAc-modified proteins $[231,232]$.

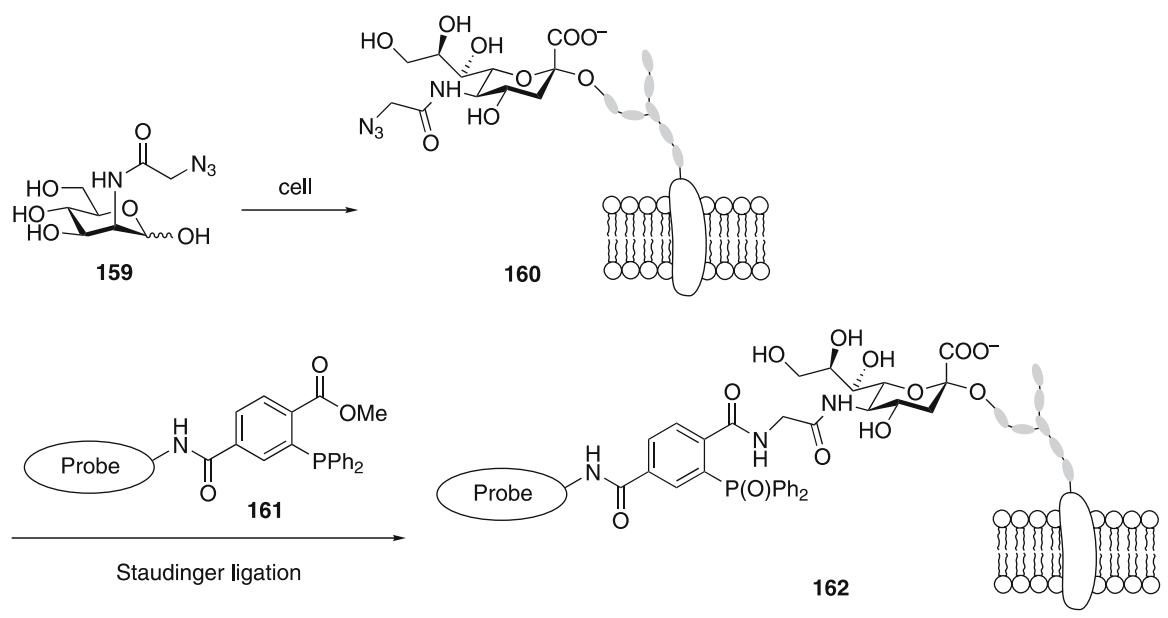

Scheme 30 Cell surface engineering by the Staudinger ligation 


\section{Conclusion}

The biological importance of glycans and the need for pure glycoforms of glycoproteins for biological studies and pharmaceutical applications have been the major driving forces toward the development of strategies for the preparation of these structures. The synthesis of glycopeptide and glycoprotein mimetics allows for structure-activity relationship studies but has many practical applications as well. Replacement of labile $\mathrm{N}$ - and $\mathrm{O}$-glycosidic bonds by more stable $C$ - and $S$-glycosides generates compounds with longer half-lives and simplifies their preparation by linear assembly strategies due to the increased stability of the corresponding building blocks. Convergent approaches using chemoselective ligation reactions provide access to homogeneous glycoprotein mimetics that are likely to impact our understanding of how specific glycoforms mediate physiological processes. Despite the progress made in the field, many challenges remain, e.g., the development of methods for the controlled introduction of multiple (different) glycans into proteins.

\section{References}

1. Lowe JB, Marth JD (2003) Annu Rev Biochem 72:643

2. Dube DH, Bertozzi CR (2005) Nat Rev Drug Discov 4:477

3. Shriver Z, Raguram S, Sasisekharan R (2004) Nat Rev Drug Discov 3:863

4. Ratner DM, Adams EW, Disney MD, Seeberger PH (2004) Chem Bio Chem 5:1375

5. Gabius H-J, Siebert H-C, André S, Jiménez-Barbero J, Rüdiger H (2004) Chem Bio Chem 5:740

6. Rudd PM, Elliott T, Cresswell P, Wilson IA, Dwek RA (2001) Science 291:2370

7. Helenius A, Aebi M (2001) Science 291:2364

8. Wittmann V (2001) Glycoproteins: properties. In: Fraser-Reid B, Tatsuta K, Thiem J (eds) Glycoscience: chemistry and chemical biology, vol III. Springer, Berlin Heidelberg New York, p 2289

9. Dwek RA (1996) Chem Rev 96:683

10. Varki A, Cummings R, Esko J, Freeze H, Hart G, Marth J (eds) (1999) Essentials of glycobiology. Cold Spring Harbor Laboratory Press, Cold Spring Harbor

11. Hang HC, Bertozzi CR (2005) Bioorg Med Chem 13:5021

12. Muramatsu T (2001) Glycoconjugate J 17:577

13. Wittmann V (2001) Glycoproteins: occurrence and significance. In: Fraser-Reid B, Tatsuta K, Thiem J (eds) Glycoscience: chemistry and chemical biology, vol III. Springer, Berlin Heidelberg New York, p 2253

14. Van den Steen P, Rudd PM, Dwek RA, Opdenakker G (1998) Crit Rev Biochem Mol Biol 33:151

15. Rudd PM, Dwek RA (1997) Crit Rev Biochem Mol Biol 32:1

16. Haase C, Seitz O (2007) In: Wittmann V (ed) Glycopeptides and glycoproteins. Topics in current chemistry, vol 276. Springer, Berlin Heidelberg New York (in press) 
17. Thayer DA, Wong C-H (2007) In: Wittmann V (ed) Glycopeptides and glycoproteins. Topics in current chemistry, vol 276. Springer, Berlin Heidelberg New York (in press)

18. Warren JD, Geng X, Danishefsky SJ (2007) In: Wittmann V (ed) Glycopeptides and glycoproteins. Topics in current chemistry, vol 276. Springer, Berlin Heidelberg New York (in press)

19. Liu L, Bennett CS, Wong C-H (2006) Chem Commun, pp 21-33

20. Wong $\mathrm{CH}$ (2005) J Org Chem 70:4219

21. Pratt MR, Bertozzi CR (2005) Chem Soc Rev 34:58

22. Hölemann A, Seeberger PH (2004) Curr Opin Biotechnol 15:615

23. Davis BG (2002) Chem Rev 102:579

24. Grogan MJ, Pratt MR, Marcaurelle LA, Bertozzi CR (2002) Annu Rev Biochem 71:593

25. Brocke C, Kunz H (2002) Bioorg Med Chem 10:3085

26. Herzner H, Reipen T, Schultz M, Kunz H (2000) Chem Rev 100:4495

27. Lee YC, Lee RT (eds) (1994) Neoglycoconjugates: preparation and applications. Academic, San Diego

28. Pachamuthu K, Schmidt RR (2006) Chem Rev 106:160

29. Langenhan JM, Thorson JS (2005) Curr Org Synth 2:59

30. Davis BG (2004) Science 303:480

31. Peri F, Nicotra F (2004) Chem Commun, pp 623-627

32. Schweizer F (2002) Angew Chem Int Ed 41:230

33. Randell KD, Barkley A, Arya P (2002) Comb Chem High Throughput Screen 5:179

34. Hang HC, Bertozzi CR (2001) Acc Chem Res 34:727

35. Dondoni A, Marra A (2000) Chem Rev 100:4395

36. Barchi JJ Jr (2000) Curr Pharm Des 6:485

37. Marcaurelle LA, Bertozzi CR (1999) Chem Eur J 5:1384

38. Taylor CM (1998) Tetrahedron 54:11317

39. Tolbert TJ, Wong C-H (2000) J Am Chem Soc 122:5421

40. Arslan T, Mamaev SV, Mamaeva NV, Hecht SM (1997) J Am Chem Soc 119:10877

41. Wang L, Schultz PG (2005) Angew Chem Int Ed 44:34

42. Röhrig CH, Retz OA, Hareng L, Hartung T, Schmidt RR (2005) Chem Bio Chem 6:1805

43. Dios A, Franck RW, Geer A, Marzabadi C, Tamarez M, Capozzi G, Menichetti S, Nativi C (1996) Angew Chem Int Ed Engl 35:777

44. Venturi F, Venturi C, Liguori F, Cacciarini M, Montalbano M, Nativi C (2004) J Org Chem 69:6153

45. Bartolozzi A, Li B, Franck RW (2003) Bioorg Med Chem 11:3021

46. Marin J, Violette A, Briand J-P, Guichard G (2004) Eur J Org Chem:3027

47. Marin J, Blaton M-A, Briand J-P, Chiocchia G, Fournier C, Guichard G (2005) Chem Bio Chem 6:1796

48. Biswas K, Coltart DM, Danishefsky SJ (2002) Tetrahedron Lett 43:6107

49. Simon RJ, Kania RS, Zuckermann RN, Huebner VD, Jewell DA, Banville S, Ng S, Wang L, Rosenberg S, et al. (1992) Proc Natl Acad Sci USA 89:9367

50. Zuckermann RN, Kerr JM, Kent SBH, Moos WH (1992) J Am Chem Soc 114:10646

51. Kim JM, Roy R (1997) Carbohydr Res 298:173

52. Hu Y-J, Roy R (1999) Tetrahedron Lett 40:3305

53. Saha UK, Roy R (1995) Tetrahedron Lett 36:3635

54. Roy R, Saha UK (1996) Chem Commun, pp 201-202

55. Saha UK, Roy R (1997) Tetrahedron Lett 38:7697

56. Kim JM, Roy R (1997) Tetrahedron Lett 38:3487 
57. Lee M-r, Lee J, Shin I (2002) Synlett, pp 1463-1466

58. Tornøe CW, Christensen C, Meldal M (2002) J Org Chem 67:3057

59. Rostovtsev VV, Green LG, Fokin VV, Sharpless KB (2002) Angew Chem Int Ed 41:2596

60. Breinbauer R, Koehn M (2003) Chem Bio Chem 4:1147

61. Kuijpers BHM, Groothuys S, Keereweer AR, Quaedflieg PJLM, Blaauw RH, van Delft FL, Rutjes FPJT (2004) Org Lett 6:3123

62. Ermolat'ev D, Dehaen W, Van der Eycken E (2004) QSAR Comb Sci 23:915

63. Ramos D, Rollin P, Klaffke W (2000) Angew Chem Int Ed 39:396

64. Ramos D, Rollin P, Klaffke W (2001) J Org Chem 66:2948

65. Roeckendorf N, Lindhorst TK (2004) J Org Chem 69:4441

66. van Ameijde J, Liskamp RMJ (2003) Org Biomol Chem 1:2661

67. Ichikawa Y, Matsukawa Y, Isobe M (2006) J Am Chem Soc 128:3934

68. Schäfer A, Klich G, Schreiber M, Paulsen H, Thiem J (1998) Carbohydr Res 313:107

69. Burger K, Böttcher C, Hennig L, Essawy SA (2004) Monatsh Chem 135:865

70. Reddy BG, Madhusudanan KP, Vankar YD (2004) J Org Chem 69:2630

71. Seeberger PH, Haase W-C (2000) Chem Rev 100:4349

72. Knapp S, Myers DS (2001) J Org Chem 66:3636

73. Knapp S, Myers DS (2002) J Org Chem 67:2995

74. Zhu X, Schmidt RR (2003) Tetrahedron Lett 44:6063

75. Zhu X, Schmidt RR (2004) Chem Eur J 10:875

76. Jobron L, Hummel G (2000) Org Lett 2:2265

77. Hummel G, Hindsgaul O (1999) Angew Chem Int Ed 38:1782

78. Cohen SB, Halcomb RL (2001) Org Lett 3:405

79. Cohen SB, Halcomb RL (2002) J Am Chem Soc 124:2534

80. Zhu X, Pachamuthu K, Schmidt RR (2003) J Org Chem 68:5641

81. Zhu X, Haag T, Schmidt RR (2004) Org Biomol Chem 2:31

82. Zhu X, Pachamuthu K, Schmidt RR (2004) Org Lett 6:1083

83. Hofsteenge J, Mueller DR, de Beer T, Loeffler A, Richter WJ, Vliegenthart JFG (1994) Biochemistry 33:13524

84. Manabe S, Ito Y (1999) J Am Chem Soc 121:9754

85. Kostír JV, Queisnerová M (1949) Chem Listy 43:277

86. Kessler H, Wittmann V, Köck M, Kottenhahn M (1992) Angew Chem Int Ed Engl 31:902

87. Bertozzi CR, Hoeprich PD, Bednarski MD (1992) J Org Chem 57:6092

88. Postema MHD (1995) C-Glycoside synthesis. CRC, Boca Raton, FL

89. Levy DE, Tang C (1995) The chemistry of C-glycosides. Elsevier, New York

90. Wellner E, Gustafsson T, Backlund J, Holmdahl R, Kihlberg J (2000) Chem Bio Chem $1: 272$

91. Gustafsson T, Saxin M, Kihlberg J (2003) J Org Chem 68:2506

92. Gustafsson T, Hedenstroem M, Kihlberg J (2006) J Org Chem 71:1911

93. Penner M, Taylor D, Desautels D, Marat K, Schweizer F (2005) Synlett, pp 212-216

94. Xu X, Fakha G, Sinou D (2002) Tetrahedron 58:7539

95. Wernicke A, Sinou D (2001) J Carbohydr Chem 20:181

96. Ousmer M, Boucard V, Lubin-Germain N, Uziel J, Augé J (2006) Eur J Org Chem, pp 1216-1221

97. Pearce AJ, Ramaya S, Thorn SN, Bloomberg GB, Walter DS, Gallagher T (1999) J Org Chem 64:5453

98. Lowary T, Meldal M, Helmboldt A, Vasella A, Bock K (1998) J Org Chem 63:9657 
99. Dondoni A, Mariotti G, Marra A (2002) J Org Chem 67:4475

100. Vincent SP, Schleyer A, Wong CH (2000) J Org Chem 65:4440

101. Ben RN, Orellana A, Arya P (1998) J Org Chem 63:4817

102. Kröger L, Henkensmeier D, Schäfer A, Thiem J (2004) Bioorg Med Chem Lett 14:73

103. Kobertz WR, Bertozzi CR, Bednarski MD (1992) Tetrahedron Lett 33:737

104. Wang Q, Linhardt RJ (2003) J Org Chem 68:2668

105. Michael K, Wittmann V, König W, Sandow J, Kessler H (1996) Int J Pept Protein Res 48:59

106. Sommermann T, Kim BG, Peters K, Peters EM, Linker T (2004) Chem Commun, pp 2624-2625

107. Caddick S, Hamza D, Wadman SN, Wilden JD (2002) Org Lett 4:1775

108. Debenham SD, Snyder PW, Toone EJ (2003) J Org Chem 68:5805

109. Lundquist JJ, Debenham SD, Toone EJ (2000) J Org Chem 65:8245

110. Dondoni A, Giovannini PP, Massi A (2004) Org Lett 6:2929

111. Leeuwenburgh MA, van der Marel GA, Overkleeft HS (2003) Curr Opin Chem Biol 7:757

112. Dominique R, Liu B, Das SK, Roy R (2000) Synthesis, pp 862-868

113. Dechantsreiter MA, Burkhart F, Kessler H (1998) Tetrahedron Lett 39:253

114. McGarvey GJ, Benedum TE, Schmidtmann FW (2002) Org Lett 4:3591

115. Liu S, Ben RN (2005) Org Lett 7:2385

116. Ben RN, Eniade AA, Hauer L (1999) Org Lett 1:1759

117. Eniade A, Murphy AV, Landreau G, Ben RN (2001) Bioconjugate Chem 12:817

118. Nolen EG, Kurish AJ, Potter JM, Donahue LA, Orlando MD (2005) Org Lett 7:3383

119. Vizvardi K, Kreutz C, Davis AS, Lee VP, Philmus BJ, Simo O, Michael K (2003) Chem Lett 32:348

120. Simo O, Lee VP, Davis AS, Kreutz C, Gross PH, Jones PR, Michael K (2005) Carbohydr Res 340:557

121. Jayakanthan K, Vankar YD (2005) Org Lett 7:5441

122. Cervigni SE, Dumy P, Mutter M (1996) Angew Chem Int Ed Engl 35:1230

123. Zhao Y, Kent SBH, Chait BT (1997) Proc Natl Acad Sci USA 94:1629

124. Rodriguez EC, Winans KA, King DS, Bertozzi CR (1997) J Am Chem Soc 119:9905

125. Rodriguez EC, Marcaurelle LA, Bertozzi CR (1998) J Org Chem 63:7134

126. Liu H, Wang L, Brock A, Wong C-H, Schultz PG (2003) J Am Chem Soc 125:1702

127. Wang L, Brock A, Herberich B, Schultz PG (2001) Science 292:498

128. Wang L, Zhang Z, Brock A, Schultz PG (2003) Proc Natl Acad Sci USA 100:56

129. Renaudet O, Dumy P (2003) Org Lett 5:243

130. Renaudet O, Dumy P (2004) Tetrahedron Lett 45:65

131. Renaudet O, Dumy P (2005) Bioorg Med Chem Lett 15:3619

132. Singh Y, Renaudet O, Defrancq E, Dumy P (2005) Org Lett 7:1359

133. Khidekel N, Arndt S, Lamarre-Vincent N, Lippert A, Poulin-Kerstien KG, Ramakrishnan B, Qasba PK, Hsieh-Wilson LC (2003) J Am Chem Soc 125:16162

134. Khidekel N, Ficarro SB, Peters EC, Hsieh-Wilson LC (2004) Proc Natl Acad Sci USA 101:13132

135. Hang HC, Bertozzi CR (2001) J Am Chem Soc 123:1242

136. Peri F, Cipolla L, La Ferla B, Dumy P, Nicotra F (1999) Glycoconjugate J 16:399

137. Cipolla L, Rescigno M, Leone A, Peri F, La Ferla B, Nicotra F (2002) Bioorg Med Chem 10:1639

138. Peri F, Cipolla L, Rescigno M, La Ferla B, Nicotra F (2001) Bioconjugate Chem 12:325

139. Peri F, Cipolla L, La Ferla B, Nicotra F (2003) C R Chim 6:635 
140. Peluso S, Imperiali B (2001) Tetrahedron Lett 42:2085

141. Peluso S, Ufret ML, O'Reilly MK, Imperiali B (2002) Chem Biol 9:1323

142. Hatanaka Y, Kempin U, Jong-Jip P (2000) J Org Chem 65:5639

143. Lee M-r, Shin I (2005) Org Lett 7:4269

144. Shinohara Y, Sota H, Gotoh M, Hasebe M, Tosu M, Nakao J, Hasegawa Y, Shiga M (1996) Anal Chem 68:2573

145. Ojala CR, Ostman JM, Ojala WH (2002) Carbohydr Res 337:21

146. Ernholt BV, Thomsen IB, Lohse A, Plesner IW, Jensen KB, Hazell RG, Liang X, Jakobsen A, Bols M (2000) Chem Eur J 6:278

147. Bendiak B (1997) Carbohydr Res 304:85

148. Lohse A, Martins R, Jørgensen MR, Hindsgaul O (2006) Angew Chem Int Ed 45:4167

149. Peri F, Dumy P, Mutter M (1998) Tetrahedron 54:12269

150. Carrasco MR, Nguyen MJ, Burnell DR, MacLaren MD, Hengel SM (2002) Tetrahedron Lett 43:5727

151. Carrasco MR, Brown RT, Serafimova IM, Silva O (2003) J Org Chem 68:195

152. Carrasco MR, Brown RT (2003) J Org Chem 68:8853

153. Filira F, Biondi B, Biondi L, Giannini E, Gobbo M, Negri L, Rocchi R (2003) Org Biomol Chem 1:3059

154. Matsubara N, Oiwa K, Hohsaka T, Sadamoto R, Niikura K, Fukuhara N, Takimoto A, Kondo H, Nishimura S-I (2005) Chem Eur J 11:6974

155. Hohsaka T, Sisido M (2002) Curr Opin Chem Biol 6:809

156. Kutterer KMK, Barnes ML, Arya P (1999) J Comb Chem 1:28

157. Arya P, Kutterer KMK, Barkley A (2000) J Comb Chem 2:120

158. Arya P, Barkley A, Randell KD (2002) J Comb Chem 4:193

159. Xian M, Fatima Z, Zhang W, Fang J, Li H, Pei D, Loo J, Stevenson T, Wang PG (2004) J Comb Chem 6:126

160. Youngquist RS, Fuentes GR, Lacey MP, Keough T (1995) J Am Chem Soc 117:3900

161. St. Hilaire PM, Lowary TL, Meldal M, Bock K (1998) J Am Chem Soc 120:13312

162. Wittmann V, Seeberger S (2000) Angew Chem Int Ed 39:4348

163. Wittmann V, Seeberger S (2004) Angew Chem Int Ed 43:900

164. Wittmann V, Seeberger S, Schägger H (2003) Tetrahedron Lett 44:9243

165. Ohta T, Miura N, Funitani N, Nakajima F, Niikura K, Sadamoto R, Guo C-T, Suzuki T, Suzuki Y, Monde K, Nishimura S-I (2003) Angew Chem Int Ed 42:5186

166. Raja KS, Wang Q, Finn MG (2003) Chem Bio Chem 4:1348

167. Pearce OMT, Fisher KD, Humphries J, Seymour LW, Smith A, Davis BG (2005) Angew Chem Int Ed 44:1057

168. Lee YC, Stowell CP, Krantz MJ (1976) Biochemistry 15:3956

169. Robinson MA, Charlton ST, Garnier P, Wang X-t, Davis SS, Perkins AC, Frier M, Duncan R, Savage TJ, Wyatt DA, Watson SA, Davis BG (2004) Proc Natl Acad Sci USA 101:14527

170. Davis NJ, Flitsch SL (1991) Tetrahedron Lett 32:6793

171. Wong SYC, Guile GR, Dwek RA, Arsequell G (1994) Biochem J 300:843

172. Bengtsson M, Broddefalk J, Dahmén J, Henriksson K, Kihlberg J, Lonn H, Srinivasa BR, Stenvall K (1998) Glycoconjugate J 15:223

173. Macmillan D, Bill RM, Sage KA, Fern D, Flitsch SL (2001) Chem Biol 8:133

174. Backes BJ, Ellman JA (1999) J Org Chem 64:2322

175. Macmillan D, Daines AM, Bayrhuber M, Flitsch SL (2002) Org Lett 4:1467

176. Macmillan D, Arham L (2004) J Am Chem Soc 126:9530

177. Dawson PE, Muir TW, Clark-Lewis I, Kent SBH (1994) Science 266:776 
178. Yamamoto N, Sakakibara T, Kajihara Y (2004) Tetrahedron Lett 45:3287

179. Marcaurelle LA, Bertozzi CR (2001) J Am Chem Soc 123:1587

180. Marcaurelle LA, Pratt MR, Bertozzi CR (2003) Chem Bio Chem 4:224

181. Pratt MR, Bertozzi CR (2003) J Am Chem Soc 125:6149

182. Galonic DP, van der Donk WA, Gin DY (2004) J Am Chem Soc 126:12712

183. Kitagawa T, Aikawa T (1976) J Biochem (Tokyo) 79:233

184. Hermanson GT (1996) Bioconjugate techniques. Academic, San Diego, p 148

185. Hansen PR, Olsen CE, Holm A (1998) Bioconjugate Chem 9:126

186. Shin I, Jung H-J, Cho J (2000) Bull Korean Chem Soc 21:845

187. Shin I, Jung H-J, Lee M-r (2001) Tetrahedron Lett 42:1325

188. Park S, Shin I (2002) Angew Chem Int Ed 41:3180

189. Park S, Lee M-r, Pyo S-J, Shin I (2004) J Am Chem Soc 126:4812

190. Zhu Y, van der Donk WA (2001) Org Lett 3:1189

191. Galonic DP, van der Donk WA, Gin DY (2003) Chem Eur J 9:5997

192. Gieselman MD, Zhu YT, Zhou H, Galonic D, van der Donk WA (2002) Chem Bio Chem 3:709

193. Macindoe WM, van Oijen AH, Boons G-J (1998) Chem Commun, pp 847-848

194. Watt GM, Boons G-J (2004) Carbohydr Res 339:181

195. Watt GM, Lund J, Levens M, Kolli VSK, Jefferis R, Boons G-J (2003) Chem Biol 10: 807

196. Davis BG, Maughan MAT, Green MP, Ullman A, Jones JB (2000) Tetrahedron: Asymmetry 11:245

197. Davis BG, Lloyd RC, Jones JB (2000) Bioorg Med Chem 8:1527

198. Lloyd RC, Davis BG, Jones JB (2000) Bioorg Med Chem 8:1537

199. Gamblin DP, Garnier P, Ward SJ, Oldham NJ, Fairbanks AJ, Davis BG (2003) Org Biomol Chem 1:3642

200. Davis BG (2001) Chem Commun, pp 351-352

201. Rendle PM, Seger A, Rodrigues J, Oldham NJ, Bott RR, Jones JB, Cowan MM, Davis BG (2004) J Am Chem Soc 126:4750

202. Gamblin DP, Garnier P, van Kasteren S, Oldham NJ, Fairbanks AJ, Davis BG (2004) Angew Chem Int Ed 43:828

203. Ramström O, Lehn J-M (2002) Nat Rev Drug Discov 1:26

204. Rowan SJ, Cantrill SJ, Cousins GRL, Sanders JKM, Stoddart JF (2002) Angew Chem Int Ed 41:898

205. Otto S, Furlan RLE, Sanders JKM (2002) Drug Discov Today 7:117

206. Lehn J-M, Eliseev AV (2001) Science 291:2331

207. Sakai S, Shigemasa Y, Sasaki T (1997) Tetrahedron Lett 38:8145

208. Ramström O, Lehn J-M (2000) Chem Bio Chem 1:41

209. Ramström O, Lohmann S, Bunyapaiboonsri T, Lehn J-M (2004) Chem Eur J 10:1711

210. Sando S, Narita A, Aoyama Y (2004) Bioorg Med Chem Lett 14:2835

211. Hotchkiss T, Kramer HB, Doores KJ, Gamblin DP, Oldham NJ, Davis BG (2005) Chem Commun, pp 4264-4266

212. Lin H, Walsh CT (2004) J Am Chem Soc 126:13998

213. van Hest JCM, Kiick KL, Tirrell DA (2000) J Am Chem Soc 122:1282

214. Kiick KL, Saxon E, Tirrell DA, Bertozzi CR (2002) Proc Natl Acad Sci USA 99:19

215. Link AJ, Tirrell DA (2003) J Am Chem Soc 125:11164

216. Link AJ, Vink MKS, Tirrell DA (2004) J Am Chem Soc 126:10598

217. Link AJ, Mock ML, Tirrell DA (2003) Curr Opin Chem Biol 14:603

218. Saxon E, Bertozzi CR (2000) Science 287:2007 
219. Lin FL, Hoyt HM, Van Halbeek H, Bergman RG, Bertozzi CR (2005) J Am Chem Soc 127:2686

220. Köhn M, Breinbauer R (2004) Angew Chem Int Ed 43:3106

221. Wang Q, Chan TR, Hilgraf R, Fokin VV, Sharpless KB, Finn MG (2003) J Am Chem Soc 125:3192

222. Gupta SS, Kuzelka J, Singh P, Lewis WG, Manchester M, Finn MG (2005) Bioconjugate Chem 16:1572

223. Kayser H, Zeitler R, Kannicht C, Grunow D, Nuck R, Reutter W (1992) J Biol Chem 267:16934

224. Keppler OT, Stehling P, Herrmann M, Kayser H, Grunow D, Reutter W, Pawlita M (1995) J Biol Chem 270:1308

225. Keppler OT, Horstkorte R, Pawlita M, Schmidt C, Reutter W (2001) Glycobiology $11: 11 \mathrm{R}$

226. Mahal LK, Yarema KJ, Bertozzi CR (1997) Science 276:1125

227. Prescher JA, Dube DH, Bertozzi CR (2004) Nature 430:873

228. Prescher JA, Bertozzi CR (2005) Nat Chem Biol 1:13

229. Dube DH, Bertozzi CR (2003) Curr Opin Chem Biol 7:616

230. Hang HC, Yu C, Kato DL, Bertozzi CR (2003) Proc Natl Acad Sci USA 100:14846

231. Vocadlo DJ, Hang HC, Kim E-J, Hanover JA, Bertozzi CR (2003) Proc Natl Acad Sci USA 100:9116

232. Laughlin ST, Bertozzi CR (2004) Glycobiology 14:1192

233. Thayer DA, Yu HN, Galan MC, Wong C-H (2005) Angew Chem Int Ed 44:4596 